\title{
Connected drug delivery devices to complement drug treatments: potential to facilitate disease management in home setting
}

This article was published in the following Dove Medical Press journal: Medical Devices: Evidence and Research

\author{
Beate Bittner' \\ Chantal Schmit Chiesi' \\ Saifuddin Kharawala ${ }^{2}$ \\ Gavneet Kaur ${ }^{2}$ \\ Johannes Schmidt' \\ 'Product Optimization, Global \\ Product Strategy, F. Hoffmann-La \\ Roche Ltd, 4070 Basel, Switzerland; \\ ${ }^{2}$ Bridge Medical Consulting Ltd, \\ Richmond, London, TW9 2SS, UK
}

Correspondence: Beate Bittner Product Optimization, Global Product Strategy, F. Hoffmann-La Roche Ltd, Grenzacher Strasse 124, CH-4070 Basel, Switzerland

Tel +4I 6I 6880412

Email beate.bittner@roche.com

\begin{abstract}
Connected drug delivery devices are increasingly being developed to support patient supervision and counseling in home setting. Features may include dosing reminders, adherence trackers, tools for patient education, and patient diaries to collect patient-reported outcomes, as well as monitoring tools with interfaces between patients and health care professionals (HCPs). Five connected devices have been selected as the basis for a review of the clinical evidence concerning the impact of electronic tools on treatment adherence and efficacy outcomes. Disease areas covered include multiple sclerosis, diabetes, hypertension, liver and renal transplant recipients, tuberculosis, hepatitis $\mathrm{C}$, clinically isolated syndrome, asthma, and COPD. From studies comparing the use of electronic feedback tools to standard of care, there is an initial evidence for a higher adherence to treatment and better outcomes among patients who use the electronic tools. To substantiate the assumption that connected devices can improve adherence in an outpatient setting over a prolonged period of time, further data from controlled randomized studies are required. Key barriers to the broader adoption of connected devices include data privacy laws that may prevent data sharing with HCPs in some countries, as well as the need to demonstrate that the tools are consistently used and generate a high-quality and reproducible database. If these challenges can be addressed in a way that is agreeable to all stakeholders, it is expected that the future value of connected devices will be to 1) facilitate and improve patient involvement in disease management in a flexible care setting, 2) enable early treatment decisions, and 3) complement value-based reimbursement models.
\end{abstract}

Keywords: home-administration, self-administration, connected drug delivery device, adherence, patient-reported outcomes, real-world evidence

\section{Introduction}

Globally, health care systems are facing challenges in managing the rapidly increasing cost of medical management, while also seeking to improve patient treatment outcomes and access to care. In this context, the so-called value-based health care agreements have been introduced in some countries. Value-based care refers to a model whereby health outcomes are measured against the cost of delivering the treatment or health care service ${ }^{1}{ }^{1}$ this differs from a fee-for-service approach, in which providers are paid according to the amount of health care services delivered.

One way to reduce health care costs and resources might be to shift patient care from hospital to home setting. ${ }^{2}$ While the availability of oral and subcutaneous (SC) dosing regimens for small molecules and biotherapeutics makes home-administration a reality for many diseases ${ }^{3}$ treatment adherence in a decentralized, uncontrolled setting 
can be negatively affected by infrequent direct interactions between patients and health care professionals (HCPs).

Thus, to ensure that patients comply with dosing regimens and to enable an ongoing dialog with HCPs, a variety of connected devices and corresponding health applications (apps) have been developed. These tools incorporate dosing reminders and educational features that help patients understand the rationale for complying with a treatment regimen. Adherence trackers capture whether patients are accurately taking the correct doses at appropriate intervals, while other apps allow patient-reported outcomes (PROs) to be recorded to enable monitoring of treatment effects as well as safety and tolerability. Information may also be accessible for payers and providers. ${ }^{4}$

Today, the potential value of electronic tools in complementing conventional treatment is generally accepted. However, there remains limited quantitative evidence on the impact of connected devices and health apps in relation to adherence to treatment, health outcomes, and overall cost effectiveness. The aims of this review article were to 1) summarize the regulatory environment within the field of connected devices and describe the regulatory status of selected devices; 2) review the impact of the selected devices on adherence to treatment and health outcomes; and 3) identify barriers that need to be overcome to unfold the full potential of these tools. The relevance of such tools in facilitating drug administration in a decentralized setting, to complement value-based health care and to facilitate early treatment decisions, is discussed. Connected devices and health apps that complement drug treatments are inscope. The so-called "stand-alone" health apps that are not used in combination with a drug are beyond the scope of this review.

\section{Materials and methods}

The connected drug delivery devices have been selected to cover a range of different indications, administration routes, and presentations (ie, connected tools available for different molecules or in combination with a specific molecule only).

Connected health solutions that are in-scope include those that

- are used as part of a drug delivery device (ie, for SC, oral, or inhaled administration) and collect device usage information with accompanying software that analyzes and reports information (ie, hardware and software). Devices can be equipped with electronic dosing reminders and/or adherence trackers
- $\quad$ are approved by the Food and Drug Administration (FDA) or European Medicines Association (EMA) and already on the market to support administration of specific drug treatments with a number of supporting clinical trials available in the literature.

Connected health solutions that are out of scope include those that

- qualify as connected drug delivery device as per above, but are not yet approved, marketed, and/or are currently in development with limited evidence available from clinical trials

- have a diagnostic purpose, such as glucose monitoring tools

- are not used as part of a drug delivery device, such as mobile apps and other software for patients and/or HCPs that enable monitoring and tracking, provide coaching or recommendations, or enable connectivity between HCPs and patients (ie, software only or software and hardware not involved in drug delivery).

On this basis, the connected devices selected were RebiSmart ${ }^{\circledR}$ (Merck KGaA, Darmstadt, Germany), BETACONNECT ${ }^{\text {TM }}$ (Bayer AG, Leverkusen, Germany), Proteus Discover (Proteus Digital Health, Inc, Redwood City, CA, USA), SmartInhaler ${ }^{\text {TM }}$ (Adherium North America, Inc, San Mateo, CA, USA; now known as Hailie ${ }^{\mathrm{TM}}$ but branded as SmartInhaler ${ }^{\mathrm{TM}}$ at the time the included studies were completed), ${ }^{5}$ and Propeller (Propeller Health, Madison, WI, USA). These technologies are either marketed in combination with one molecule (RebiSmart ${ }^{\circledR}$ with interferon $\beta$-1a, BETACONNECT ${ }^{\mathrm{TM}}$ with interferon $\beta-1 \mathrm{~b}$ ), or marketed or developed for use with different molecules (Proteus, SmartInhaler ${ }^{\mathrm{TM}}$, and Propeller). The principal characteristics of these selected devices are summarized in Table 1. Tools that may allow an ongoing dialog between patients and HCPs, patient monitoring, or the collection of PRO data are available with some of the devices, but are not consistently applied in the different clinical studies discussed.

Targeted searches were run to characterize the devices and to address the research questions for each device. Key research questions are summarized in Table S1. The searches were conducted using PubMed, Google, Google Scholar, company websites, regulatory databases, health technology assessment (HTA) databases, and trial registries (Table S2). Specific search terms used for the different devices are listed in Table S3. Potentially relevant references for each device were initially identified using title/abstract screening, and full texts were retrieved. Full texts were then screened, and all publications relevant to the research questions were included in this review. 


\begin{tabular}{|c|c|c|c|c|c|}
\hline 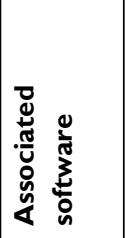 & 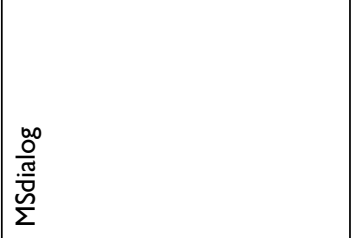 & 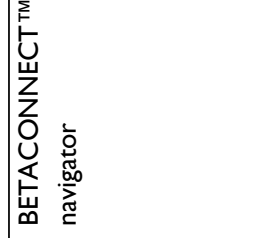 & 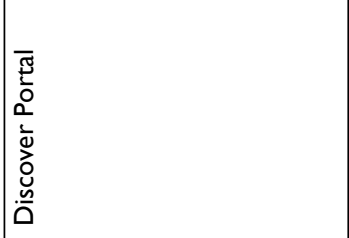 & 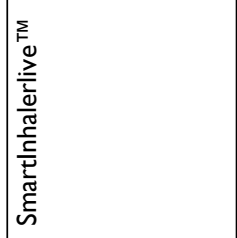 & 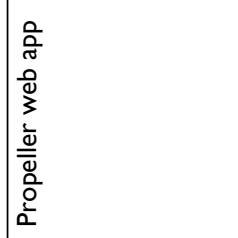 \\
\hline 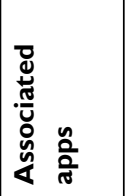 & $\begin{array}{l}0 \\
\frac{0}{\alpha} \\
0 \\
0 \\
\frac{0}{\sigma 0} \\
\overline{0} \\
\frac{\omega}{\Sigma}\end{array}$ & 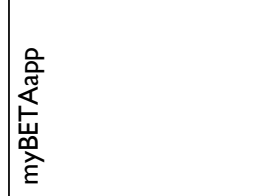 & 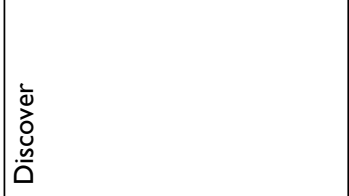 & 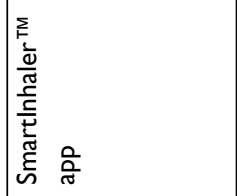 & 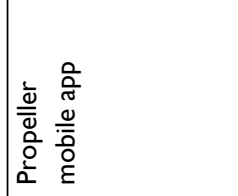 \\
\hline 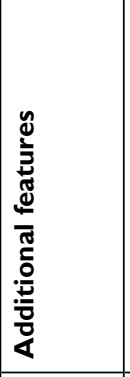 & 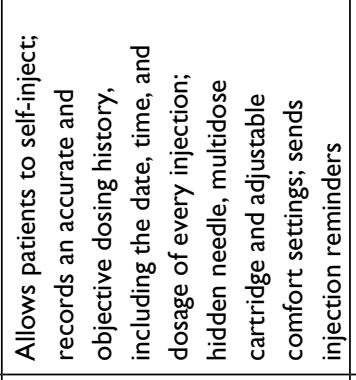 & 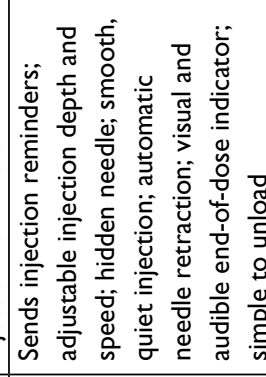 & 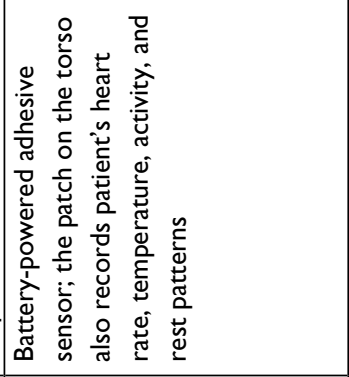 & 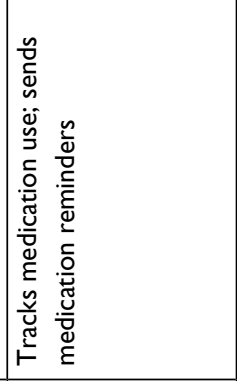 & 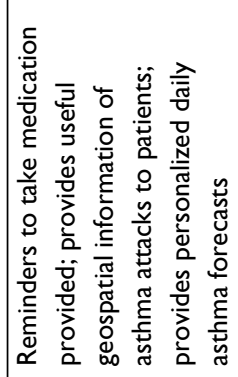 \\
\hline 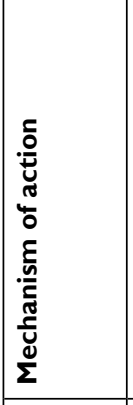 & 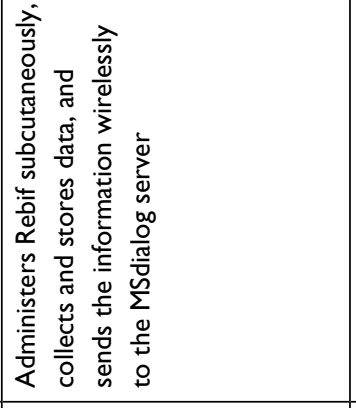 & 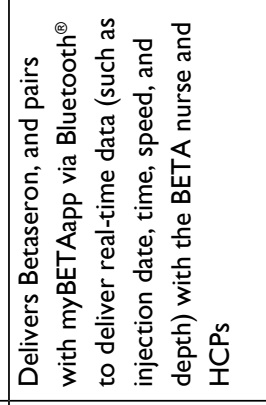 & 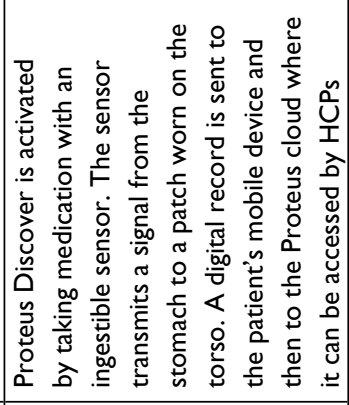 & 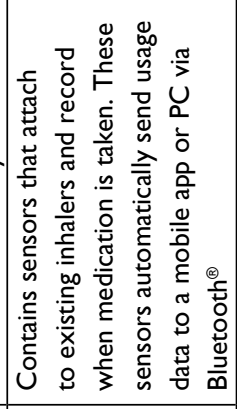 & 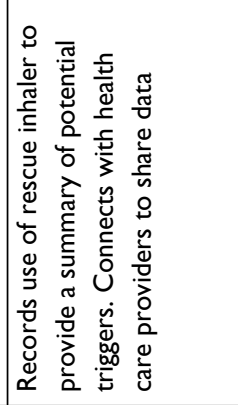 \\
\hline 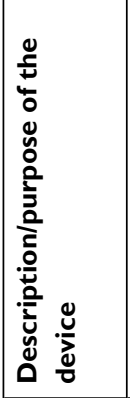 & 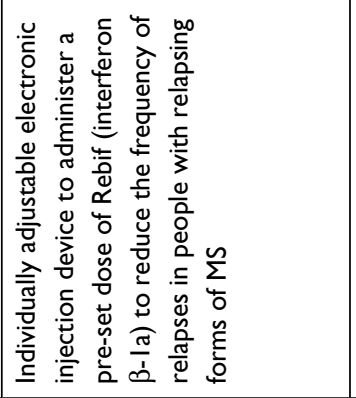 & 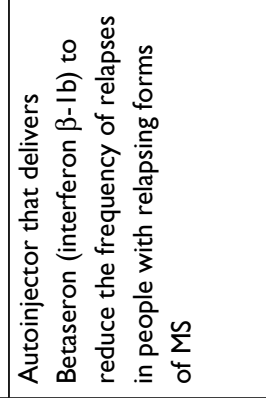 & 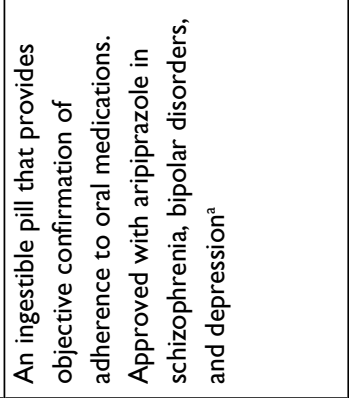 & 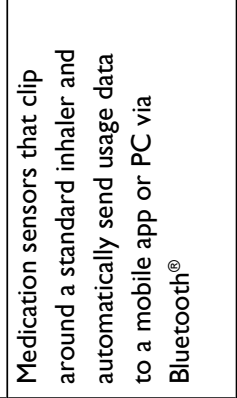 & 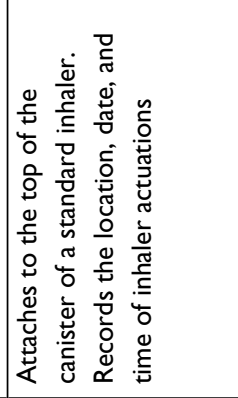 \\
\hline 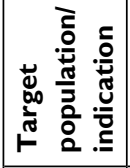 & $\sum$ & $\sum$ & 资 & 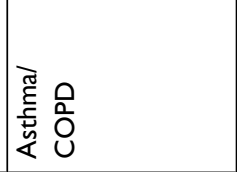 & 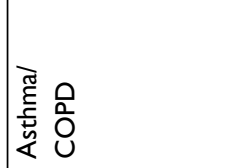 \\
\hline 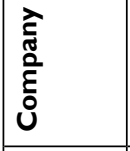 & 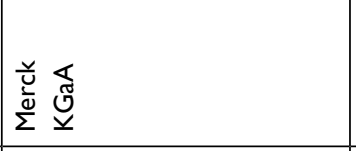 & 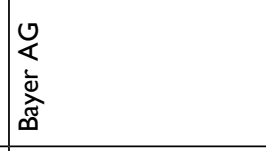 & 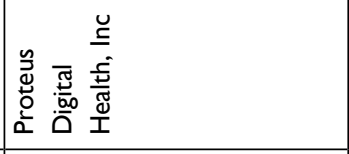 & 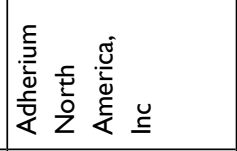 & 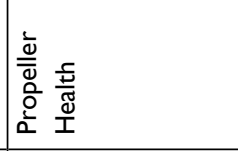 \\
\hline ڤัٌ & 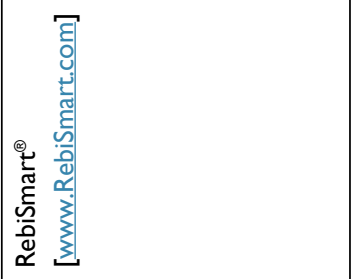 & 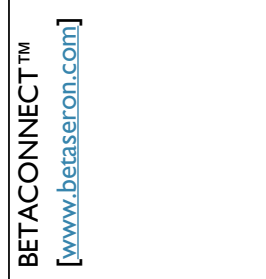 & 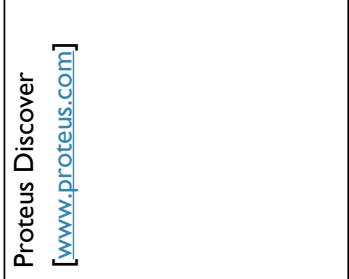 & 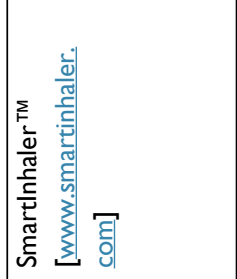 & 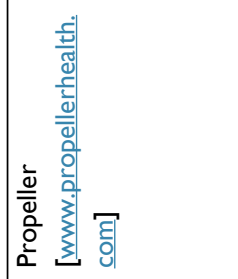 \\
\hline
\end{tabular}




\section{Results}

Regulatory guidance for connected devices and health apps (US and EU)

\section{US medical device definitions and classifications}

As an integral part of drug treatment and patient monitoring, connected devices and related health apps can meet the definition of a medical device. To market a medical device in the United States (US), manufacturers require the submission of a Premarket Notification 510(k) prior to commercial distribution, and the FDA issues a "letter of substantial equivalence" confirming that the device is considered substantially equivalent to one legally in commercial distribution in the US. ${ }^{6}$ Similarly, in the European Union (EU), medical device commercialization requires a Conformité Européene (CE) mark that indicates compliance with specific standards of performance, quality, safety, and efficacy EU regulations. In case a medical device is associated with a specific treatment, additional regulatory requirements that also consider approval of the accompanying active substance need to be fulfilled. ${ }^{7}$

Devices are generally classified according to the risk they pose to consumers. In the US, connected devices and health apps that meet the definition of a medical device can be classified as either Class I, with the lowest risk (eg, smart devices and health apps helping users to self-manage their disease without providing specific clinical suggestions), or Class II and III, encompassing complex devices with a high risk (eg, health apps that can control another medical device or provide a patient-specific diagnosis or treatment). Most Class I devices and some Class II devices are exempt from Premarket Notification $510(\mathrm{k}){ }^{6}$

In the EU, according to the 2017 Medical Device Directive $2017 / 745,{ }^{7}$ health apps can be considered as non-medical devices or classified as Class I (low risk), IIa (low/medium risk), IIb (medium/high risk), or III (high risk). This classification takes into account 23 rules that consider the function, the patient's risk, and the manufacturer's intended use of the device. ${ }^{7}$ Under Directive 2017/745, software for diagnostic or therapeutic purposes is classified as Class IIa, and under certain conditions could even be included in Class IIb or III.

\section{Regulatory status for selected devices}

The regulatory status for the five selected devices in this section are based on publicly available information.

Approval status of selected connected devices (US) In the US, premarket $510(\mathrm{k})$ approvals with regulatory Class II classification were obtained for devices not involving specific medications (Proteus Discover, SmartInhaler ${ }^{\mathrm{TM}}$, and Propeller). ${ }^{8}$ Furthermore, $510(\mathrm{k})$ approvals were obtained at multiple times; that is, whenever any substantial changes were made to the devices. ${ }^{8}$

For devices associated with specific treatments such as BETACONNECT ${ }^{\mathrm{TM}}$ with interferon $\beta-1 \mathrm{~b}$ and Proteus Discover with aripiprazole, the approval pathway involved different steps. For BETACONNECT ${ }^{\mathrm{TM}}$, supplemental Biologics License Application letters were submitted. ${ }^{9}$ A New Drug Application (NDA) was opened for Proteus Discover with aripiprazole. ${ }^{10}$ In an initial rejection letter, the FDA asked for data under real-world conditions, evaluation of use-related risks, and confirmation that customers could use the device safely and effectively. ${ }^{10}$ Proteus Discover approval was based on the NDA resubmission that contained data from "human factors validation studies." 10 The RebiSmart ${ }^{\circledR}$ is not filed in the US.

\section{Approval status of selected smart devices (EU)}

In the EU, all approved devices received a CE mark. ${ }^{11-14}$ For Proteus Discover, a submission was made to the EMA to issue a favorable opinion considering the use of Proteus technology as a "qualified method" for measuring adherence and associated relevant physiologic and behavioral parameters, such as indications of therapeutic response. The Committee for Medicinal Products for Human Use (CHMP) gave a favorable opinion for the same and noted that "if the device is intended to be marketed with a specific medicinal product, a relevant benefit/risk assessment will be carried out at time of marketing authorization application depending on the dossier." ${ }^{15}$ BETACONNECT ${ }^{\mathrm{TM}}$ is not filed in the EU.

\section{Impact of selected connected devices on adherence, clinical outcomes, and health care resource use}

Adherence and clinical outcomes data were available for all selected connected devices. Data for the impact on health care costs and resource utilization were limited, with evidence available only for Propeller and the SmartInhaler ${ }^{\mathrm{TM}}$. The majority of clinical studies identified were uncontrolled trials (single-arm, prospective, or retrospective cohorts).

Key findings from the respective studies are presented in the following sections. For each device, randomized controlled trials (RCTs) and/or larger non-RCTs are described in detail, with statistical significance and smaller studies summarized in the respective tables. To assess the impact of patient age on adherence to treatment, the age of the study population as well as its impact on adherence rates is 
listed, if applicable. Where available, the focus is on trials that compare use of a connected device vs a non-connected device or standard of care.

\section{RebiSmart $^{\circledR}$}

RebiSmart $^{\circledR}$ is an individually adjustable electronic injection device developed to facilitate the SC self-injection of interferon $\beta$-1a for the treatment of multiple sclerosis (MS) and includes injection reminders and a web-, tablet-, and smartphone-based software app to collect and store real-time adherence, clinician-reported outcomes, and PRO data. ${ }^{16,17}$

RebiSmart $^{\circledR}$ clinical studies identified in the search are detailed in Table 2 and include MS patients treated three times weekly with SC interferon $\beta$-1a. None of the trials compared RebiSmart ${ }^{\circledR}$ against standard of care without electronic tools. As no RCTs have been conducted using RebiSmart $^{\circledR}$, data from the three largest uncontrolled studies are described below.

In a multicenter observational study, 912 RMS patients self-administered SC interferon $\beta$-1a using the RebiSmart ${ }^{\circledR}$ autoinjector three times weekly for 12 months or until early discontinuation (ED). ${ }^{18}$ The primary endpoint of mean cumulative adherence for the safety population, defined as the proportion of expected injections completed as captured by the autoinjector, was $97.1 \%$. Mean adherence rates did not appear to differ by time since starting interferon $\beta$-1a before study entry - rates ranged from $96.7 \%$ to $97.3 \%$ across the categories. Mean adherence per patient since the last visit at month $12 / \mathrm{ED}$ was $96.5 \%$. To assess the impact of full treatment adherence on disease activity, a clean patient subset (all data available, no open queries) was separately analyzed. In this analysis ( $\mathrm{n}=720)$, a significantly higher proportion of patients treated with high-dose interferon $\beta$-1a ( $\geq 120 \mu \mathrm{g} /$ week) were relapse-free at month 6 compared with patients with lower doses (92.5\% vs $86.7 \%$, respectively), and a nonsignificant trend was observed at month $12 / \mathrm{ED}(82.1 \%$ vs $76.6 \%)$. At month $12 / \mathrm{ED}, 72.4 \%$ of highly adherent patients (defined as cumulative adherence $>75 \%$ ) and $41.2 \%$ of patients with a lower adherence were relapse-free. The mean annual relapse rate (ARR) was 0.3 in highly adherent patients and 0.6 in less adherent patients.

In a multicenter, retrospective, observational study, data from 258 relapsing-remitting multiple sclerosis (RRMS) patients who received interferon $\beta$-1a treatment using RebiSmart $^{\circledR}$ for 36 months or until treatment discontinuation were analyzed. ${ }^{19}$ Adherence was based on the number of SC administrations from treatment initiation to device replacement or treatment discontinuation. Overall adherence was $92.6 \%$, while $32 \%$ achieved an adherence rate of $100 \%, 80.6 \%$ achieved adherence $\geq 90 \%$, and $13.2 \%$ showed adherence $<80 \%$. An analysis by quarter revealed a slight decrease in adherence over time, with a mean overall adherence of $94.0 \%$ at $0-3$ months and $90.4 \%$ at the time of device replacement. Over the study period, the incidence of relapses decreased from $5.8 \%$ at $0-3$ months to $4.0 \%$ at 33-36 months. Suboptimal adherence (adherence of $<80 \%$ ) was about three times higher in subjects with relapses compared with those without relapses.

In a multicenter, retrospective, observational study, 384 RRMS patients self-administered interferon $\beta$-1a three times weekly using RebiSmart ${ }^{\circledR}$ for a period of 12 months. ${ }^{20}$ Overall, $89.3 \%$ of patients were adherent to treatment $(\geq 80 \%$ of the scheduled injections were administered). At 12 months follow-up, adherence rates varied significantly by age groups with the highest adherence rate (93.2\%) in those aged $26-40$ years, followed by $87.5 \%$ in patients aged $\geq 41$ years, and $79 \%$ in those aged $\leq 25$ years. Moreover, $90.5 \%$ of patients with a baseline Expanded Disability Status Scale (EDSS) $<4$ showed $\geq 80 \%$ adherence (vs $71.4 \%$ in patients with EDSS score $\geq 4$ ).

A number of smaller uncontrolled trials with follow-up periods between 12 weeks and 1.5 years revealed high adherence of $\geq 80 \%-90 \% .{ }^{21-27}$ Lugaresi et al $^{28,29}$ found a decrease in adherence (among completers) from 100\% through week 4 to $99.1 \%$ in weeks $5-8$, to $89.0 \%$ in weeks $9-12$. After a long-term follow-up of 20.5 months, overall adherence was further decreased to $79.8 \%$. Ghezzi et al ${ }^{30}$ reported declining adherence rates over the study period, with 12-, 24-, and 52-week adherence rates of $82.5 \%, 80.0 \%$, and $67.5 \%$, respectively.

While in the majority of trials conducted with the RebiSmart $^{\circledR}$, the impact of patient age on adherence was either not assessed or no statistically significant correlation could be detected, Zecca et $\mathrm{l}^{25}$ found a statistically significant impact of higher age on objective adherence (Table 2). Median age as per adherence rates was 41.0 years in patients with low adherence rates, 48.5 years in patients with medium adherence, and 53.5 years in patients with high adherence rates.

Predictors for adherence were assessed in a number of these smaller uncontrolled studies. In a retrospective analysis of data from RRMS patients, Moccia et $\mathrm{al}^{22}$ found that missing the first dose during the first month of observation was more likely to be associated with clinical relapse, as well as with a significantly lower adherence to treatment compared with fully adherent patients or patients who 


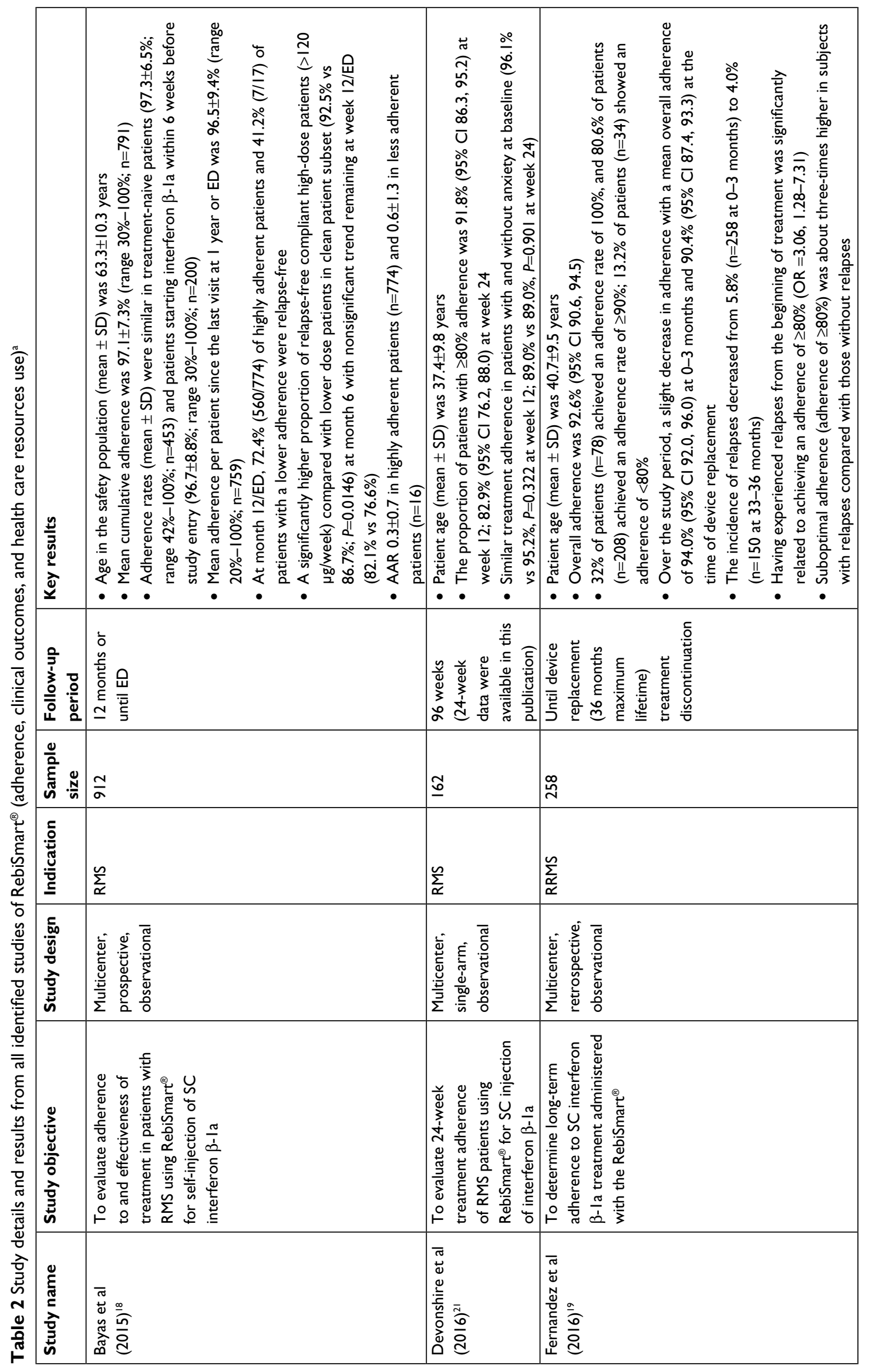




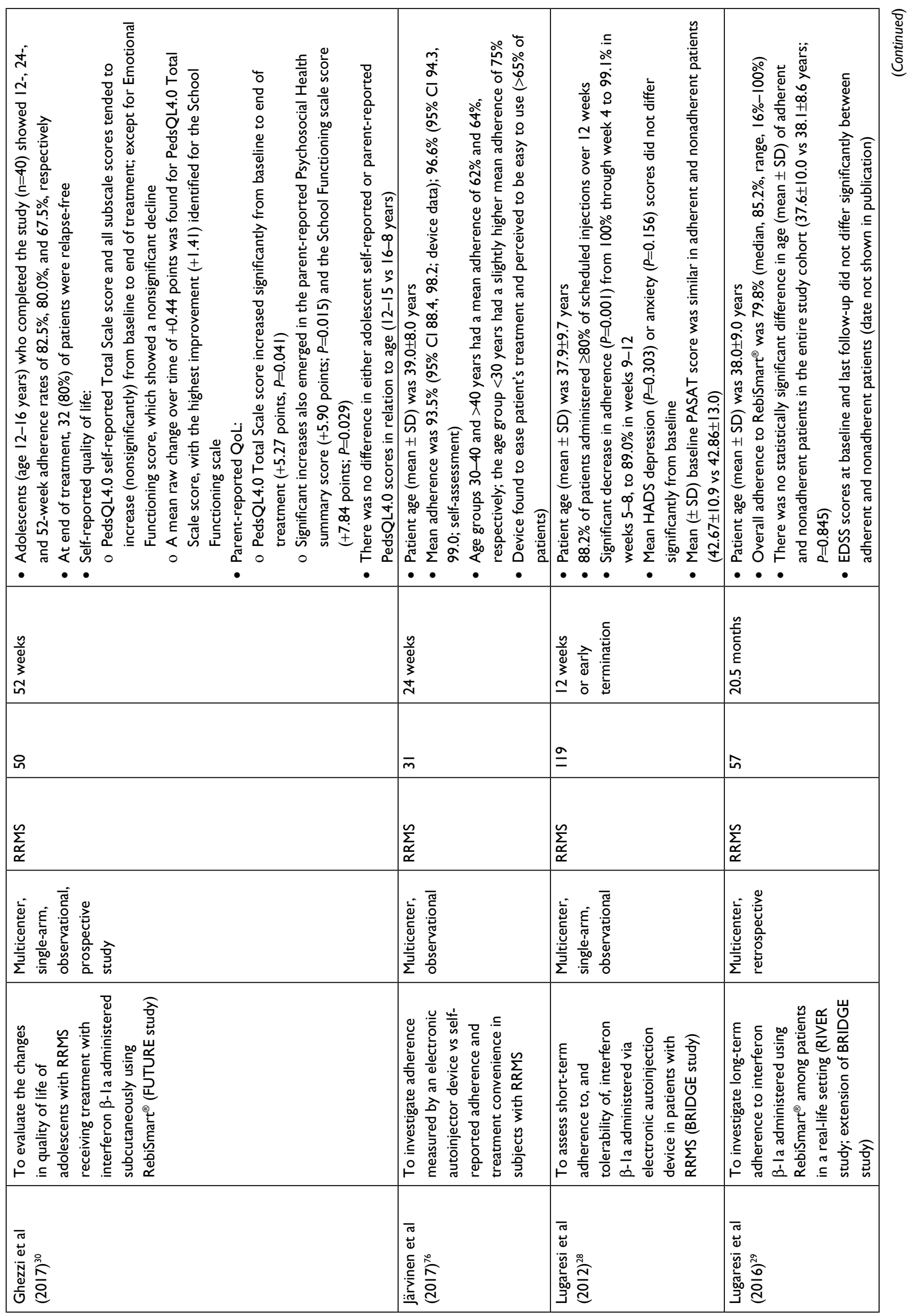




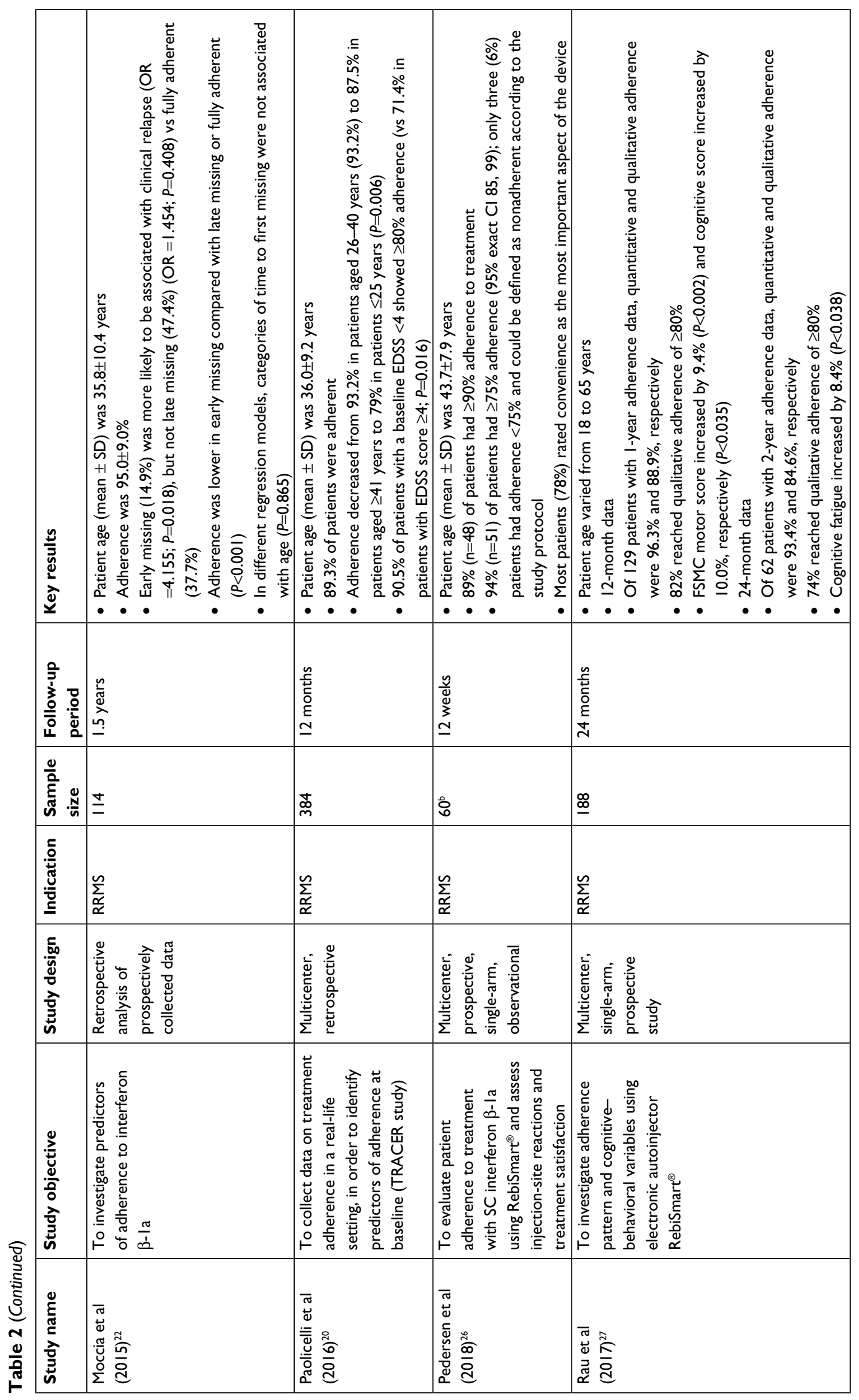




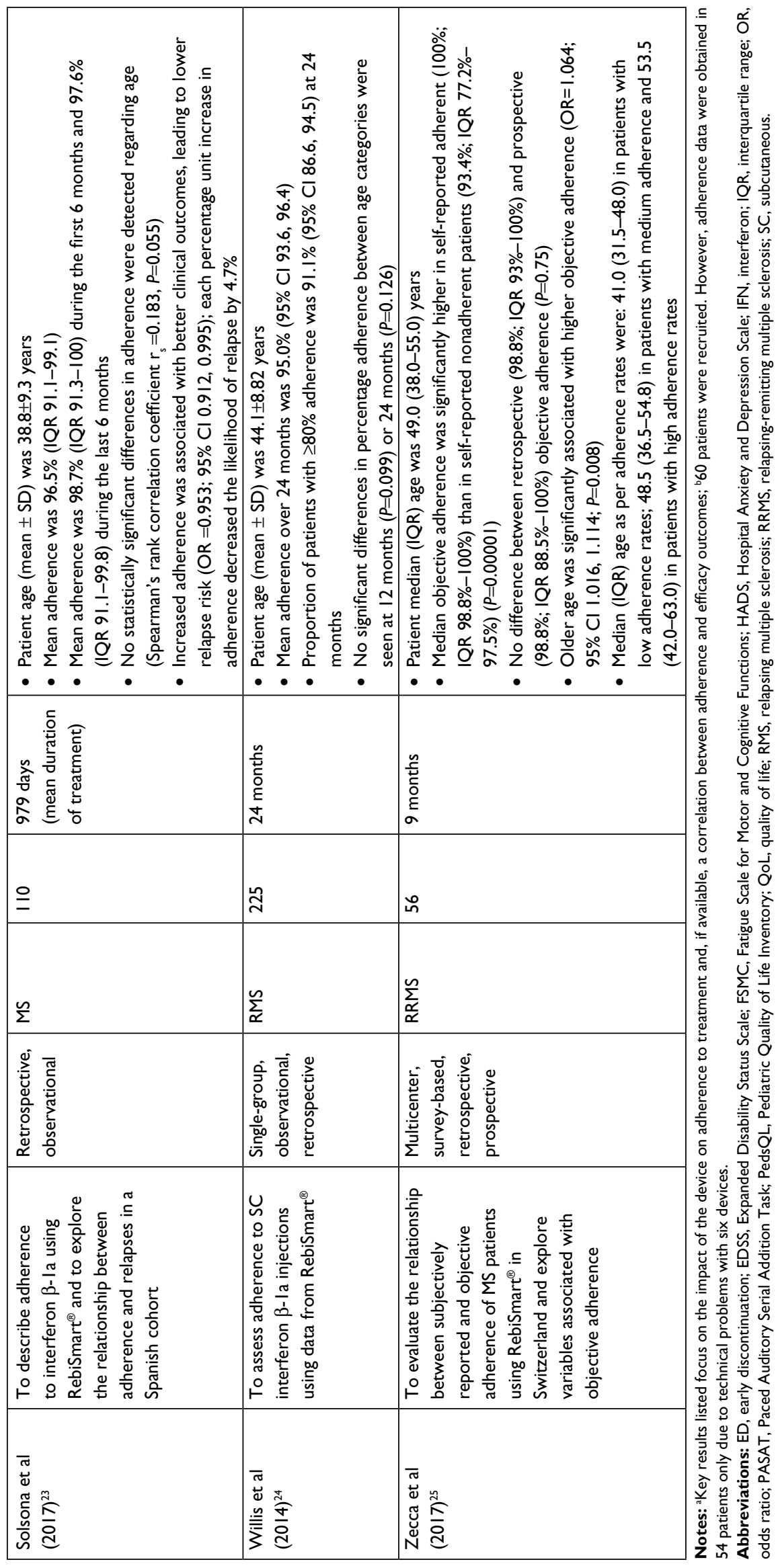


missed a dose at a later point. A correlation between high adherence and a high proportion of relapse-free patients and a very low annualized relapse rate was reported by Solsona et al. ${ }^{23}$

\section{BETACONNECT TM}

The BETACONNECT ${ }^{\mathrm{TM}}$ autoinjector system, designed to simplify SC injections of interferon $\beta$ - 1 b automatically, collects data on injection date and time, injection depth, injection speed, and injection volume. The system offers injection reminders and can transfer data to an optional mobile phone app/computer program and a navigator app to enhance communication between patients and HCPs. ${ }^{31}$

Key outcomes from clinical studies identified for BETACONNECT $^{\mathrm{TM}}$ are detailed in Table 3 . As no RCT has been conducted with the BETACONNECT ${ }^{\mathrm{TM}}$ device, data from the three published uncontrolled studies in MS patients treated with SC interferon $\beta-1 b$ are described below.

In a prospective, observational, 24-week cohort study in 151 patients with RRMS or clinically isolated syndrome (CIS) treated with interferon $\beta-1 b$ using the BETACON$\mathrm{NECT}^{\mathrm{TM}}$ autoinjector, adherence (defined as percentage of patients injecting $\geq 80 \%$ of prescribed dosages with at least one BETACONNECT ${ }^{\mathrm{TM}}$ readout) declined from $72.0 \%$ at week 4 to $67.3 \%$ at week 12 and $57.9 \%$ at week $24 .{ }^{32}$ Premature study discontinuation was the main reason for this decline in adherence $(11.2 \%$ at week $4,22.4 \%$ at week 12 , and $29 \%$ at week 24 ). The proportion of adherent patients at each respective visit was high over the study period $(81.1 \%$ at week $4,86.7 \%$ at week 12 , and $80.5 \%$ at week 24 ). Key predictors for persistence (defined as the number of patients still using the device at the follow-up visit) were age and "no previous treatment" - patients $\geq 40$ years were more likely to still be using the device at follow-up than patients $<40$ years, and treatment-naive patients were more likely to be persistent than those who were previously treated with interferon $\beta-1 b$.

In a multicenter, prospective, single-arm, observational 24-week study in 474 RRMS and 26 CIS patients treated with interferon $\beta$ - $1 \mathrm{~b}$ using BETACONNECT ${ }^{\mathrm{TM}}$, median adherence (defined as completing $\geq 80 \%$ of prescribed injections) remained stable at between $93.9 \%$ and $95.4 \%$ at all visits. ${ }^{33}$ Higher adherence was associated with male gender, existing concomitant disease, shorter disease duration, higher Symbol Digit Modalities Test (SDMT) score, and higher satisfaction with the myBETAapp.

A smaller study in 89 RRMS patients with a 6-month observation period reported a mean adherence rate of $97.6 \%$, with $95.5 \%$ of patients reaching $\geq 80 \%$ adherence. ${ }^{34}$

\section{Proteus Discover (ingestible sensors)}

The Proteus system uses ingestible sensors that communicate wirelessly to a patch worn on the body to accurately document medication adherence for oral medications. These data, as well as medication reminders, are sent to the patients' mobile phone. Data can be shared with HCPs, allowing them to view adherence. ${ }^{35}$

For Proteus Discover, a number of RCTs and prospective trials have been identified (Table 4). Adherence was not a primary objective in most of the studies, with the focus tending to be on efficacy outcomes or cost savings using the Proteus technology. Indications included tuberculosis, hepatitis $\mathrm{C}$, hypertension, type 2 diabetes mellitus (T2DM), hypercholesterolemia, and liver and renal transplant recipients. RCTs comparing Proteus technology to standard of care, as well as economic model studies, are described below.

In a cluster-randomized, prospective, open-label trial with a 12-week intervention period, 109 patients with T2DM (hemoglobin A1c $[\mathrm{HbA1c}] \geq 7$ ) and hypertension (systolic blood pressure $[\mathrm{SBP}] \geq 140 \mathrm{mmHg}$ ) were randomized to receive medicine in combination with the Proteus ingestible sensor for 4 or 12 weeks, or usual care. ${ }^{36}$ In the Proteus groups, the medical sensor and the medication were coencapsulated to ensure that both were taken simultaneously. The Proteus group investigators were instructed to review the adherence reports on the web portal during study visits and provide patient education/counseling or titrate medications as needed, based on these reports, in addition to other clinical data. Medication adherence, calculated only for the Proteus ingestible sensor, was $>80 \%$ (not a trial objective).

In hypertension, at week 4, the combined Proteus groups had a mean change in SBP from baseline of $-21.8 \mathrm{mmHg}$ vs $-12.7 \mathrm{mmHg}$ for usual care. In addition, a greater proportion of participants in the Proteus groups achieved their BP goal (81\%) compared with usual care (33.3\%). At week 12, 98\% of Proteus participants achieved their BP goal vs $51.7 \%$ of usual care participants. ${ }^{36}$

In diabetes, there was a nonsignificant difference in HbA1c reduction in favor of the Proteus groups (4-week Proteus group mean, $-0.32 \% ; 12$-week Proteus group mean, $-0.08 \%$; usual care mean, $0.28 \%$ ). For participants with a baseline $\mathrm{HbA} 1 \mathrm{c} \geq 8 \%$, the Proteus groups experienced a larger HbA1c decrease compared with an HbA1c increase in the usual care group (difference from 4-week Proteus group, $-0.98 \%$; difference from 12-week Proteus group, $-0.57 \%$ ). Differences in change in low-density lipoprotein cholesterol (LDL-C) between the Proteus groups and the usual care group were $-33.2 \mathrm{mg} / \mathrm{dL}$ at week 4 and $-19.2 \mathrm{mg} / \mathrm{dL}$ at week $12 .{ }^{36}$ 


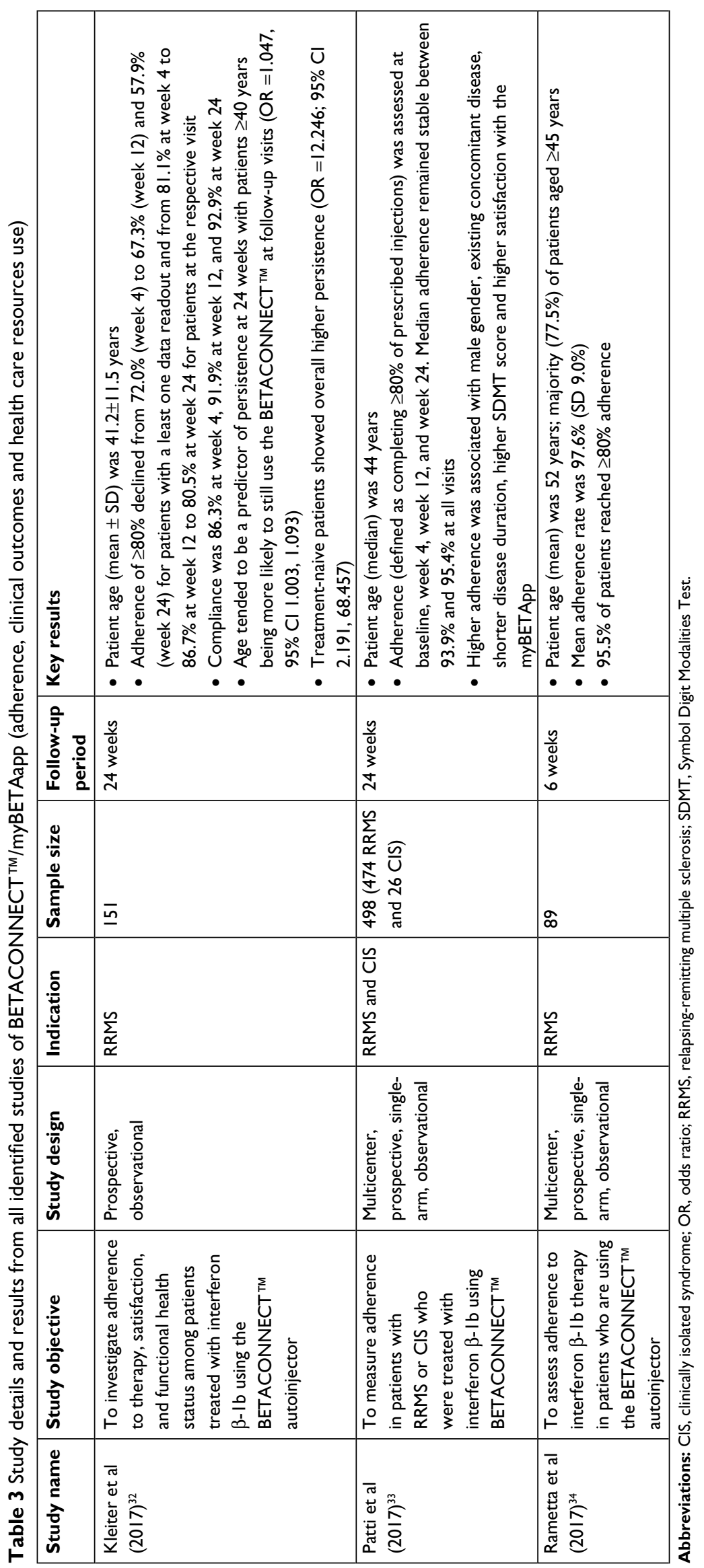




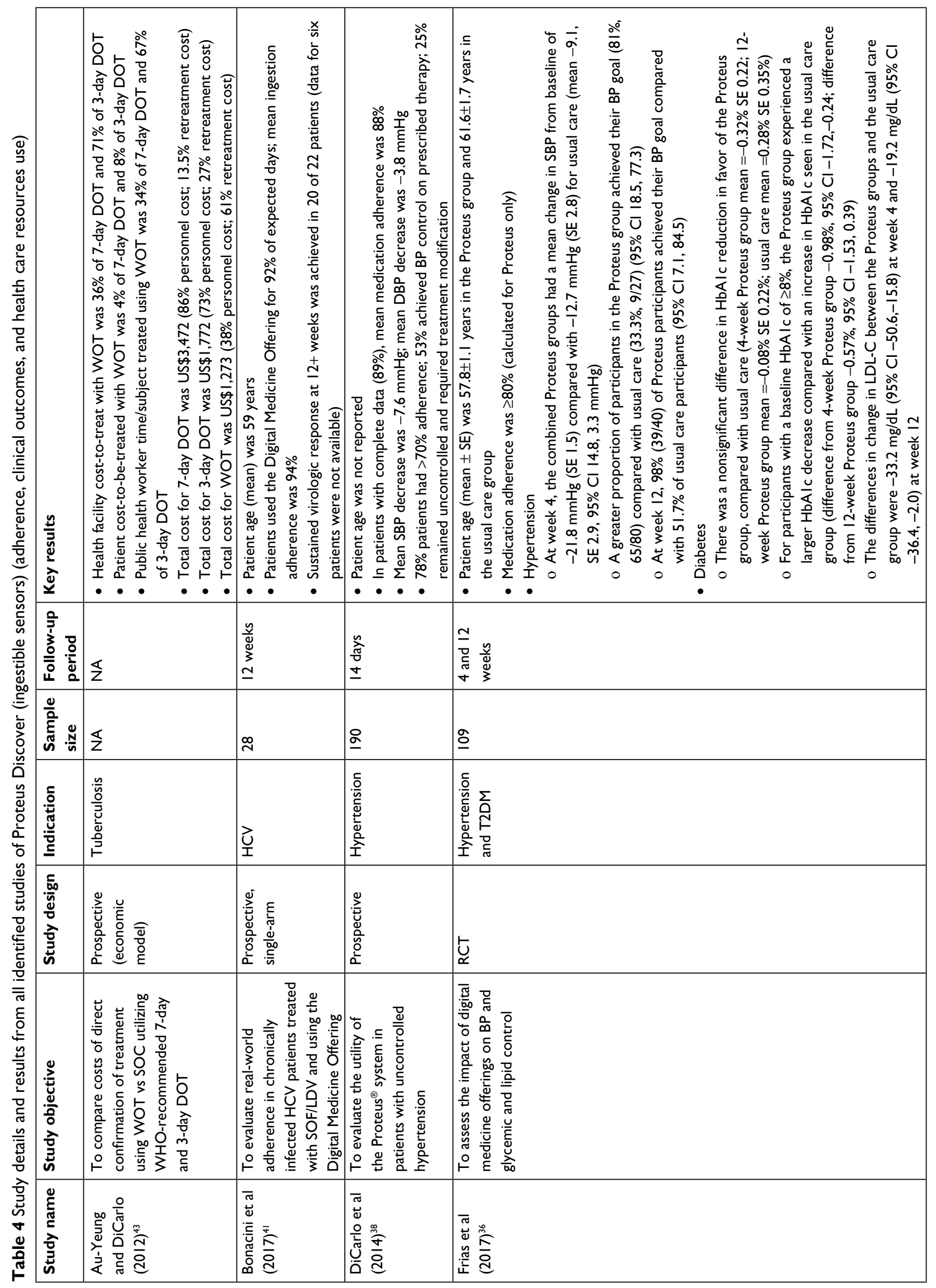




\begin{tabular}{|c|c|c|c|c|c|c|c|}
\hline 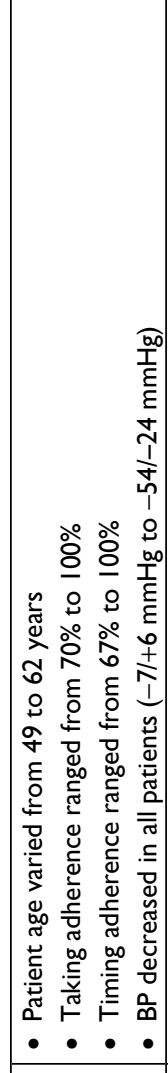 & 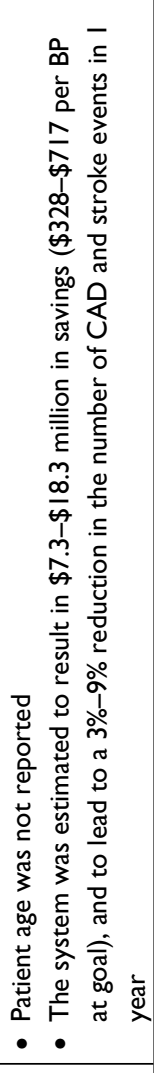 & 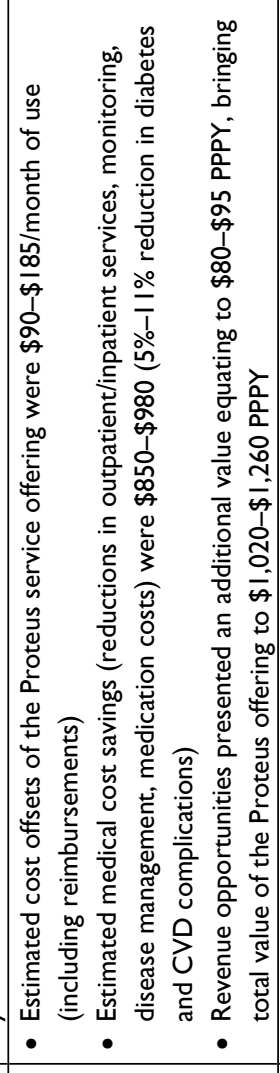 & 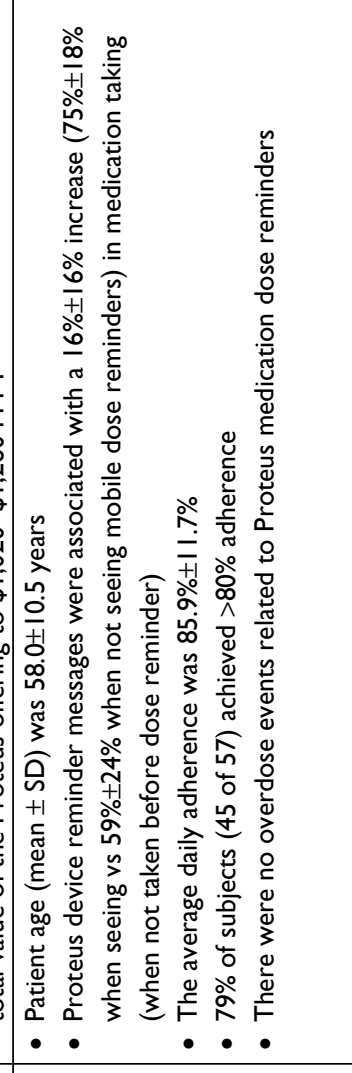 & 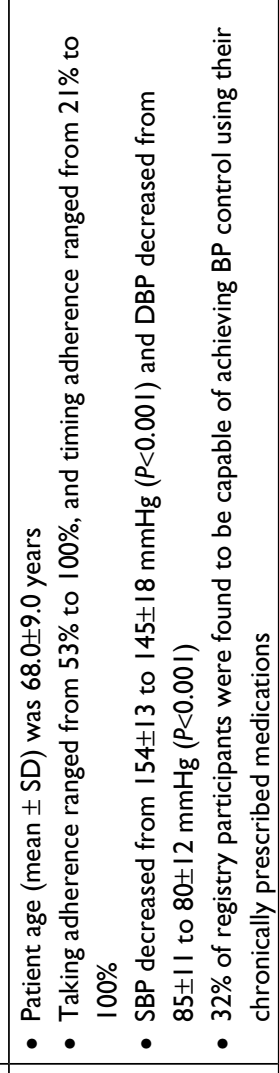 & 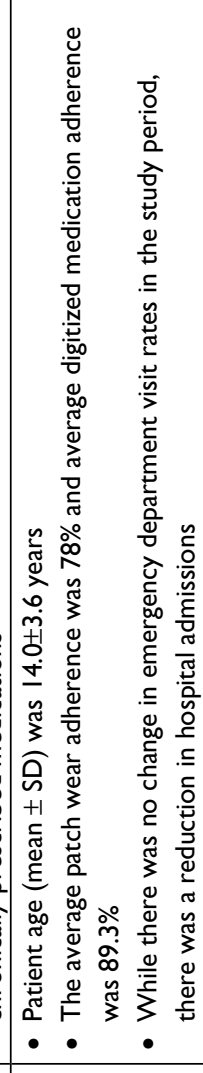 & 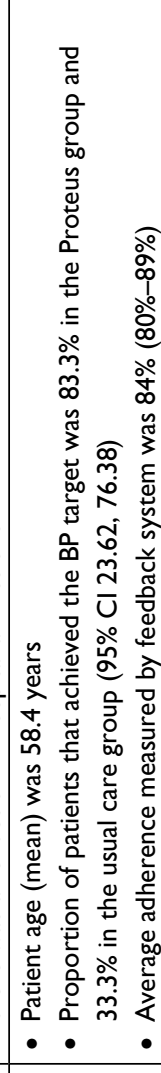 & 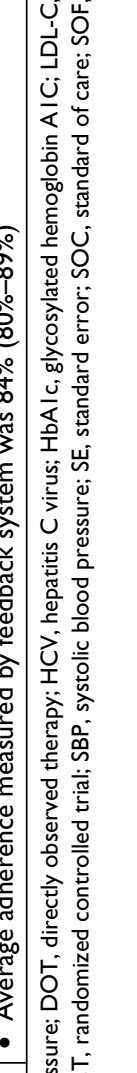 \\
\hline & 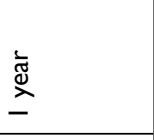 & 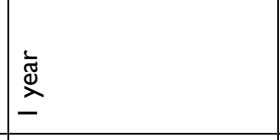 & 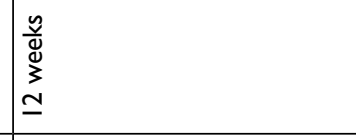 & 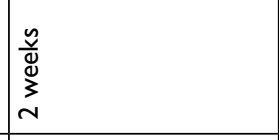 & 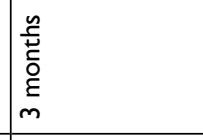 & 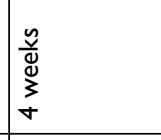 & \\
\hline$\infty$ & $\underline{\underline{\Xi}}$ & 孚 & in & $\underline{\underline{0}}$ & 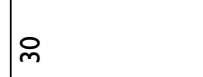 & $\underline{m}$ & \\
\hline 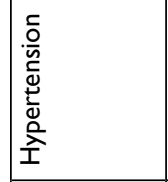 & & 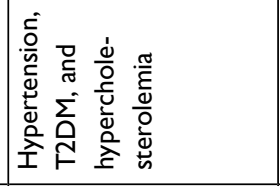 & 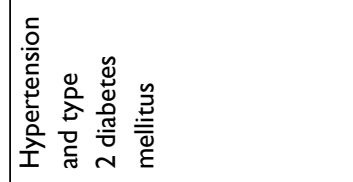 & 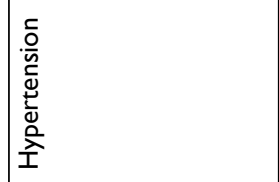 & 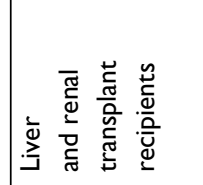 & 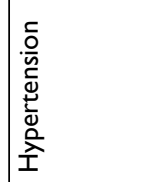 & \\
\hline 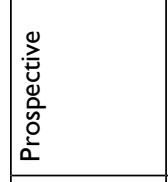 & 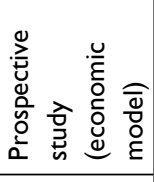 & 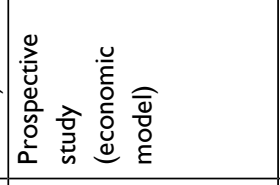 & 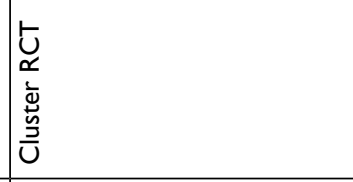 & 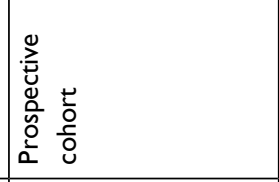 & 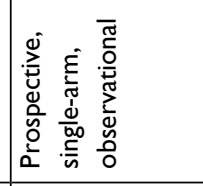 & 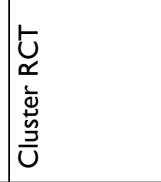 & \\
\hline 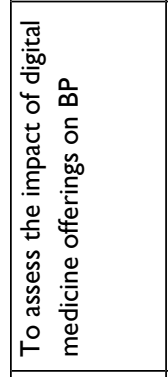 & 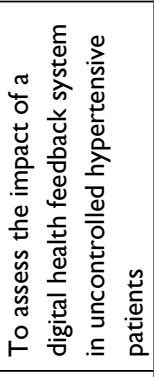 & 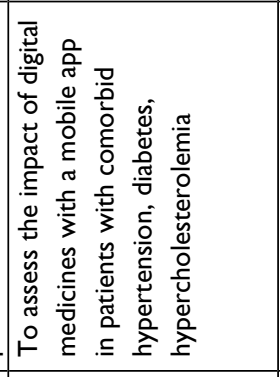 & 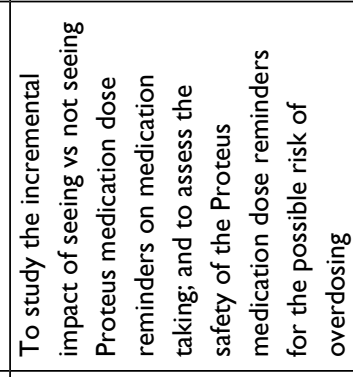 & 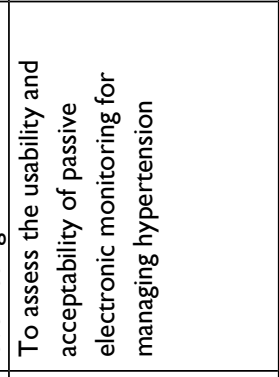 & 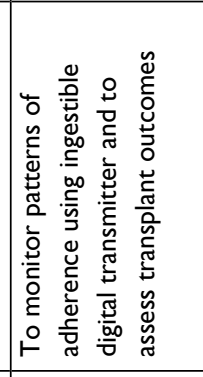 & 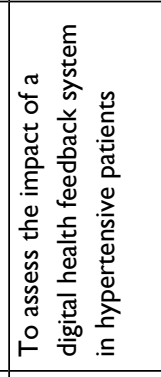 & e \\
\hline 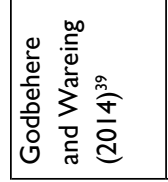 & 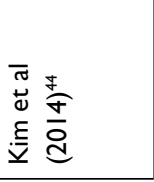 & 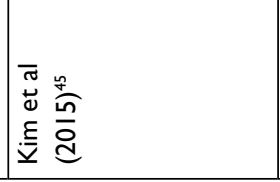 & 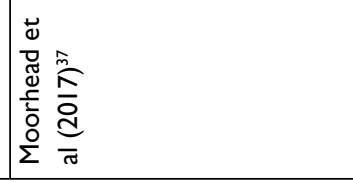 & 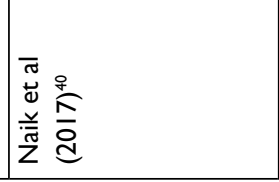 & 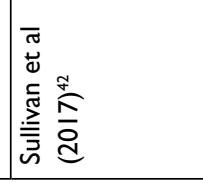 & 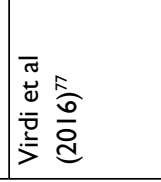 & to \\
\hline
\end{tabular}


In a cluster RCT in 57 hypertension and T2DM patients with a 12-week follow-up, Proteus Discover-derived medication dose reminders were associated with a $16 \%$ increase in medication taking vs no reminder messages. ${ }^{37}$ Average daily adherence was 85.9 , and $79 \%$ of subjects achieved $>80 \%$ adherence. Moreover, there were no overdose events related to Proteus medication dose reminders.

In other uncontrolled studies with comparatively short observation periods ( $2-4$ weeks), adherence was typically $>80 \%$ in patients with hypertension, ${ }^{38-40}$ hepatitis $\mathrm{C},{ }^{41}$ or liver and renal transplant recipients. ${ }^{42}$ Godbehere and Wareing ${ }^{39}$ and Naik et $\mathrm{al}^{40}$ distinguished between "taking adherence" (the number of ingestible sensors detected over the number of prescribed sensors) and "timing adherence" (the number of sensors detected within \pm 2 hours of the average time of all detections for the dosing period). A trend for higher variability in timing adherence was observed compared with taking adherence.

No formal assessment of the impact of age on adherence rates was conducted in the studies reported for the Proteus device.

The impact of using Proteus technology on health care costs has been analyzed for treatment of tuberculosis, hypertension, T2DM, and hypercholesterolemia. Au-Yeung and DiCarlo ${ }^{43}$ compared the impact of wirelessly observed tuberculosis therapy (WOT) using Proteus technology with WHO-recommended standard of care, 7-day and 3-day directly observed therapy (DOT). Using treatment data from public sources, it was calculated that the cost of WOT would be $36 \%$ of 7 -day DOT and $71 \%$ of 3-day DOT in a public health facility's cost-to-treat analysis. In other words, the total cost for 7-day and 3-day DOT were estimated US $\$ 3,472$ and US $\$ 1,772$, respectively, while the total cost for WOT was estimated US\$1,273.

Kim et a ${ }^{44}$ estimated the impact of the Proteus technology on outpatient services, monitoring, and cardiovascular complications in uncontrolled hypertensive patients. From a study that assessed the potential of the technology in 164 patients with a history of uncontrolled hypertension, the authors estimated that the Proteus system could result in cost savings of \$7.3-18.3 million in a health plan of 1 million members and could lead to a $3 \%-9 \%$ reduction in the number of coronary artery disease (CAD) and stroke events in 1 year. In 2015, Kim et al calculated the value of Proteus on reducing BP, blood glucose levels, and lipids in patients with comorbid hypertension, diabetes, and hypercholesterolemia. ${ }^{45}$ The model was based on costs from the Medicare Fee schedule, Agency for Health care Research and Quality
(AHRQ) databases, payer interviews, clinical and utilization assumptions from the literature, expert opinions, as well as a study using the Proteus technology in patients with uncontrolled hypertension. The authors estimated that cost offsets for Proteus would be \$90-185/month of use (including reimbursements) and that medical cost savings (reductions in outpatient/inpatient services, monitoring, disease management, medication costs) would be $\$ 850-\$ 980$ per patient per year $(5 \%-11 \%$ reduction in diabetes and CVD complications).

\section{SmartInhaler ${ }^{\mathrm{TM}}$}

The SmartInhaler ${ }^{\mathrm{TM}}$ platform includes adherence trackers for patients and HCPs, dosing reminders, and allows insights into medication usage. SmartInhaler ${ }^{\mathrm{TM}}$ medication sensors wrap around a patient's existing dry powder or metered-dose inhaler and automatically send usage data to their smartphone using Bluetooth ${ }^{\circledR}$. The corresponding app analyzes, stores, and monitors inhaler use. ${ }^{46}$

Both RCTs and prospective studies in asthma patients have been conducted with the SmartInhalerTM (Table 5), with RCT data comparing SmartInhaler ${ }^{\mathrm{TM}}$ to standard of care described in detail below.

In an open-label, parallel group RCT, 90 children aged 6-16 years on regular inhaled corticosteroids (ICSs) with poorly controlled asthma were randomized to electronic adherence monitoring using SmartInhaler ${ }^{\mathrm{TM}}$ with daily reminder alarms together with feedback in the clinic (active intervention) or to adherence monitoring alone (usual care) ${ }^{47}$ The study had a 12-month follow-up, with clinic visits at 3 months intervals. Adherence rate (calculated for each 3-month period) was calculated as percentage of the number of doses actually taken vs number of doses prescribed. There was a statistically significant difference in adherence ( $70 \%$ for active intervention vs $49 \%$ control). There was no significant difference in change in Asthma Controlled Questionnaire (ACQ), but children in the intervention group required significantly fewer courses of oral steroids and fewer hospital admissions.

In a randomized study of 220 children aged 6-15 years with asthma exacerbation treated with ICS, audiovisual reminder functions (AVRFs) on the SmartInhaler ${ }^{\mathrm{TM}}$ device used with a preventer inhaler was either enabled (intervention group) or disabled (control group). ${ }^{48}$ The follow-up period was 6 months, and adherence was defined as the proportion of ICS taken relative to the number of doses prescribed. Median adherence was $84 \%$ and $30 \%$ in the intervention and control groups, respectively. In addition to the improved adherence, improvement in asthma morbidity score from baseline to 


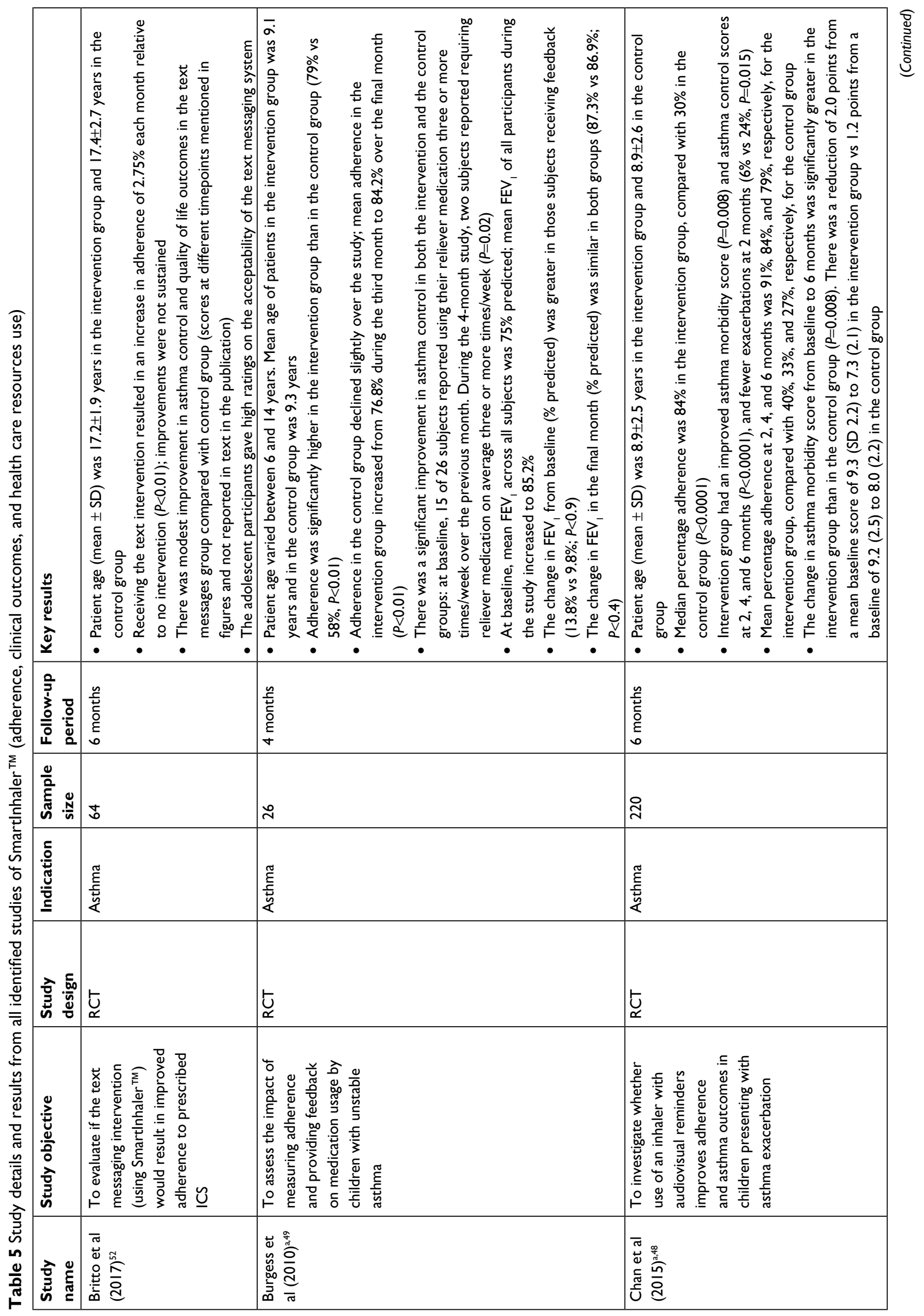




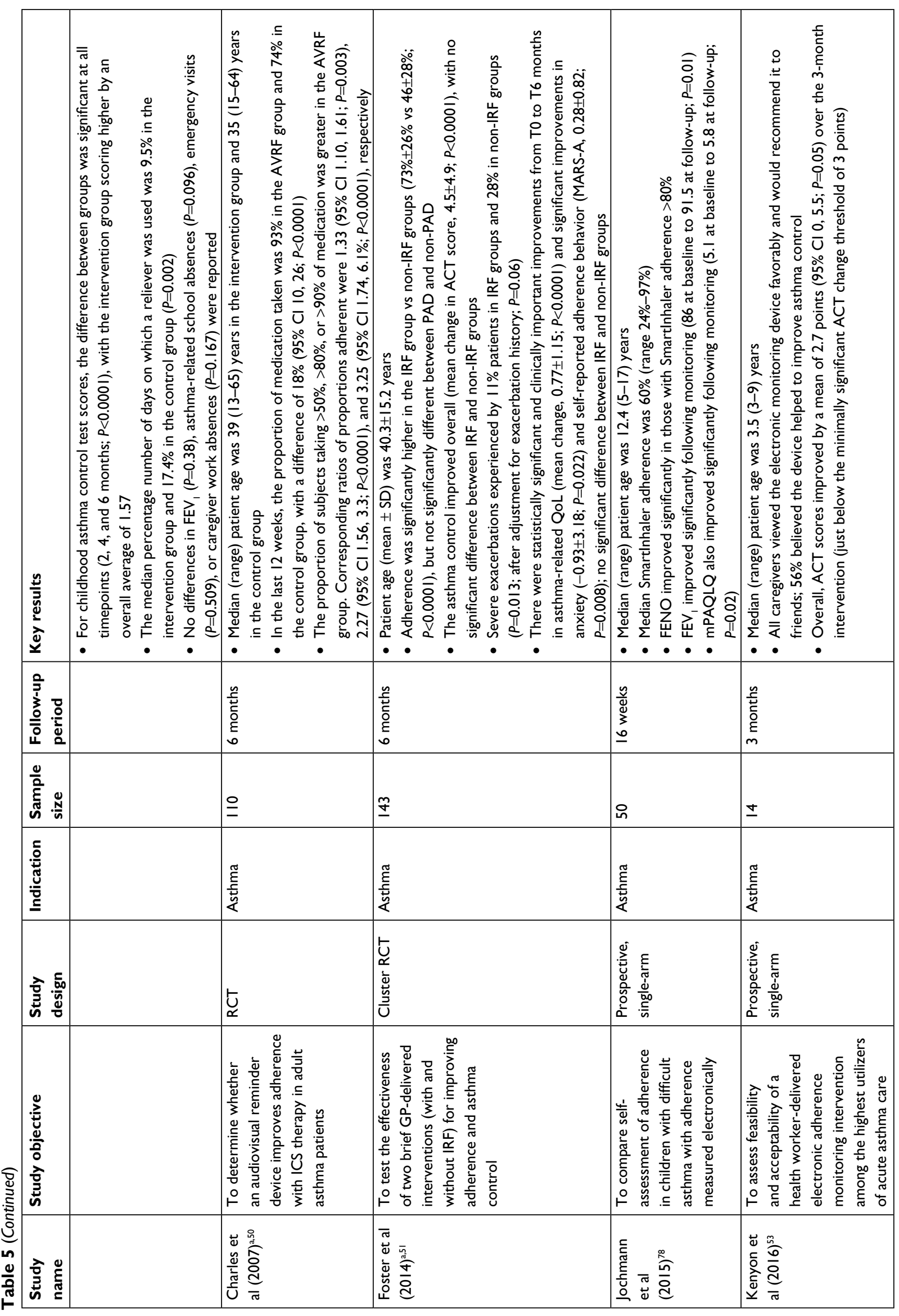




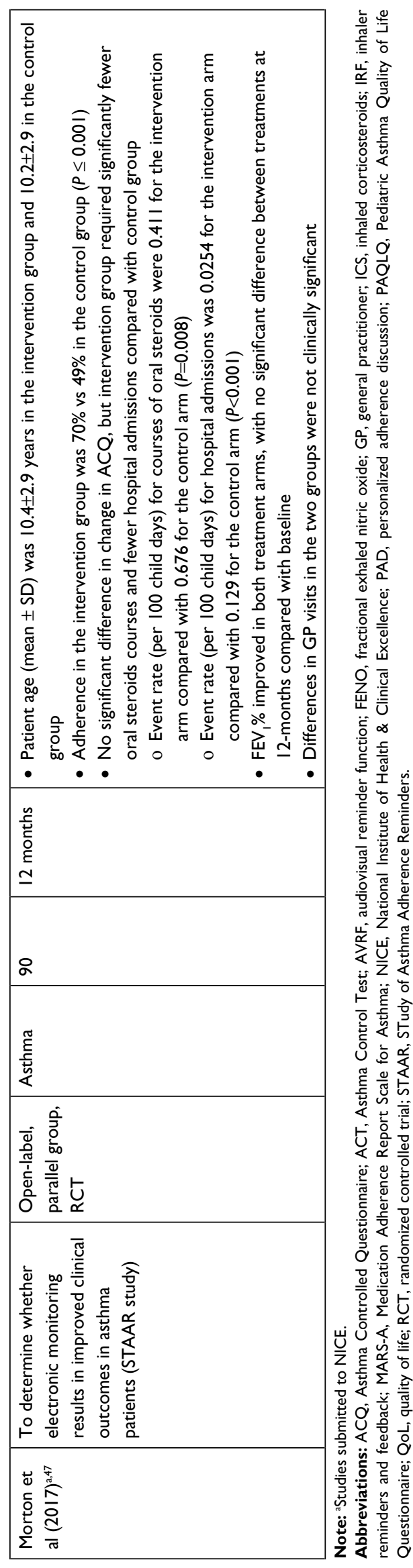

6 months was significantly greater in the intervention group (from 9.3 to 7.3) than in the control group (from 9.2 to 8.0). In addition, there were fewer exacerbations at 2 months in the intervention group than in the control group ( $6 \%$ vs $24 \%$ ), but no differences in $\mathrm{FEV}_{1}$, asthma-related school absences, emergency visits, or caregiver work absences.

In a smaller study with a follow-up period of 4 months, 26 children aged 6-14 years were randomized to being informed of their adherence (intervention group) or for their adherence to remain undisclosed (control group). Adherence was collected by means of the SmartInhalerTM. Similar to Chan et $\mathrm{al},{ }^{48}$ it was found that while adherence was significantly higher in the intervention group ( $79 \%$ vs $58 \%$ ), this was not reflected in a statistically significant improvement in lung function. ${ }^{49}$ The change in $\mathrm{FEV}_{1}$ from baseline was $13.8 \%$ in the intervention group vs $9.8 \%$ in the control group, and the mean $\mathrm{FEV}_{1}$ in the final month was $87.3 \%$ and $86.9 \%$, respectively, in the two groups.

In a randomized open-label parallel group study with a follow-up of 24 weeks, 110 adult or adolescent asthma patients taking ICS were randomized to receiving their medication with or without an AVRF. ${ }^{50}$ Adherence (defined as the proportion of medication taken as prescribed over the final 12 weeks of the study) was $93 \%$ in the AVRF group and $74 \%$ in the control group. In addition, the proportions of subjects taking $>50 \%,>80 \%$, or $>90 \%$ of their medication were greater in the AVRF group.

In a cluster RCT, with general practitioner (GP) as a unit of cluster, GPs were trained to deliver the relevant intervention(s) with 143 patients from their own practice prescribed twice-daily ICS/long-acting $\beta_{2}$-agonist for $\geq 1$ month with a follow-up of 6 months. ${ }^{51}$ GPs were randomized to one of the following four groups: usual care (UC) $(n=43$ patients); $\mathrm{UC}+$ personalized adherence discussions (PAD, $\mathrm{n}=24$ patients); usual care + inhaler reminders and feedback (IRF) ( $\mathrm{n}=35$ patients); UC + IRF + PAD ( $\mathrm{n}=41$ patients). Adherence was significantly higher in the IRF (73\%) than in non-IRF groups $(46 \%)$, and there was no statistically significant difference between PAD and non-PAD groups. Asthma Controlled Test (ACT) scores improved overall (mean change, 4.5), and a significant difference among IRF and non-IRF groups was observed. About $11 \%$ and $28 \%$ of patients experienced severe exacerbations in the IRF and nonIRF groups, respectively. Overall, there were no significant differences between the reminder and non-reminder groups in any other secondary outcome.

In a randomized crossover study in 64 adolescent asthma patients, Britto et $\mathrm{al}^{52}$ investigated the impact of text 
messaging using SmartInhaler ${ }^{\mathrm{TM}}$ on adherence to prescribed ICS. All patients underwent 3 months of receiving personalized text messages such as medication or appointment reminders or other messages of their choice (intervention arm) and 3 months without access to the text messaging tool (control arm) in a randomized order. Receiving text reminders resulted in a $2.75 \%$ increase in adherence each month, while adherence decreased in the absence of text messages. In the group that received text messages first, intervention effects were not sustained on switching to control, and adherence decreased.

No formal assessment of the impact of patient age on adherence rate was conducted in the studies reported for the SmartInhaler ${ }^{\mathrm{TM}}$.

To assess the feasibility and acceptability of health worker-delivered electronic adherence monitoring, a prospective cohort 3-month pilot study was performed in which 14 children (median age, 3.5 years) with the highest frequency of asthma-related emergency department and hospital care within a local managed care Medicaid plan were enrolled. ${ }^{53}$ The intervention included motivational interviewing, electronic monitoring of controller and rescue inhaler use, and outreach by a community health worker for predefined medication alerts. All participants initiated the use of the electronic devices, but no modem signal was transmitted after a mean of 45 days for five patients. All caregivers viewed the electronic monitoring device favorably and would recommend it to friends; $56 \%$ believed the device helped to improve asthma control.

Morton et $\mathrm{al}^{47}$ reported a trend in the reduction in GP/ emergency department visits and days off school due to asthma in the SmartInhaler ${ }^{\mathrm{TM}}$ group. This difference was, however, not statistically significant. Results from multivariate analysis showed that patients receiving usual care were $\sim 1.5$ times more likely to be prescribed oral steroids (incidence rate ratio [IRR]: 1.53 ) and also had $\sim 4.5$ times higher rate of hospital admissions (IRR: 4.38) compared with the SmartInhaler ${ }^{\mathrm{TM}}$ group.

SmartInhalers ${ }^{\mathrm{TM}}$ were subject to a National Institute of Health \& Clinical Excellence (NICE) HTA. ${ }^{13}$ The review included five RCTs in adults and children assessing asthma control using ACQ scores, medication adherence, proportion of prescribed doses taken, and days absent from school for patients using SmartInhalers ${ }^{\mathrm{TM}}$ as highlighted in Table 5.

While an improved adherence with the SmartInhaler ${ }^{\mathrm{TM}}$ technology was found across studies, NICE noted that "key uncertainties are that some of the available studies were either not designed to or were not adequately powered to show whether improved adherence is associated with significantly improved outcomes." It concluded that the evidence for these possible resource consequences is limited and that the resource impact would be greater than standard care, because of the cost of the device and software access ( $£ 100$ per unit [exclusive of VAT], plus $£ 14.17$ per month for each HCP to access cloud-based data), unless reductions in GP and hospital visits were realized.

\section{Propeller}

The Propeller system includes an electronic inhaler sensor that attaches to an existing third-party inhaler. The sensor monitors the date, time, and frequency of medication use and transmits these data back to secure servers through a smartphone app or hub-base station. Location data are collected on medication use among patients who have a smartphone. The sensors regularly transmit data back to the server or sync through the smartphone or hub. ${ }^{54}$ Similar to the SmartInhaler ${ }^{\mathrm{TM}}$ technology, Propeller is used for a variety of differed inhaler types.

Both RCTs and prospective studies in patients with asthma and COPD have been conducted with the Propeller system (Table 6). Data from RCTs and larger uncontrolled studies that compared the use of Propeller to standard of care are described in detail below. Use of rescue inhaler was monitored in most of the studies. While some studies highlight the use of a short-acting $\beta$-agonist (SABA), others did not mention the name of the rescue inhaler.

In an RCT enrolling 495 asthma patients with a SABA prescription at study intake, patients either received access to and feedback from the Propeller system, with physicians able to monitor patient status (intervention group) or routine care whereby patients were fitted with sensors, but did not receive feedback. ${ }^{55}$ The follow-up period was 12 months. The mean daily number of SABA uses per person decreased by 0.41 for the intervention group and by 0.31 for routine care between the first week and the end of study. In addition, the proportion of SABA-free days increased by $21 \%$ for the intervention group and $17 \%$ for routine care. ACT scores were not significantly different between arms. There was a greater improvement in the proportion of patients with controlled asthma in the intervention group vs routine care $(63 \%$ vs 49\%) among adults with initially uncontrolled asthma.

In a 6-month RCT, 125 adult asthma patients with a SABA prescription were randomized to an intervention (electronic inhaler sensors tracking medication use, electronic data visualizations, reminders, and personalized education) or control group (received sensors, but with no data access for the patient or care manager). ${ }^{56}$ In addition to a 21 -point 


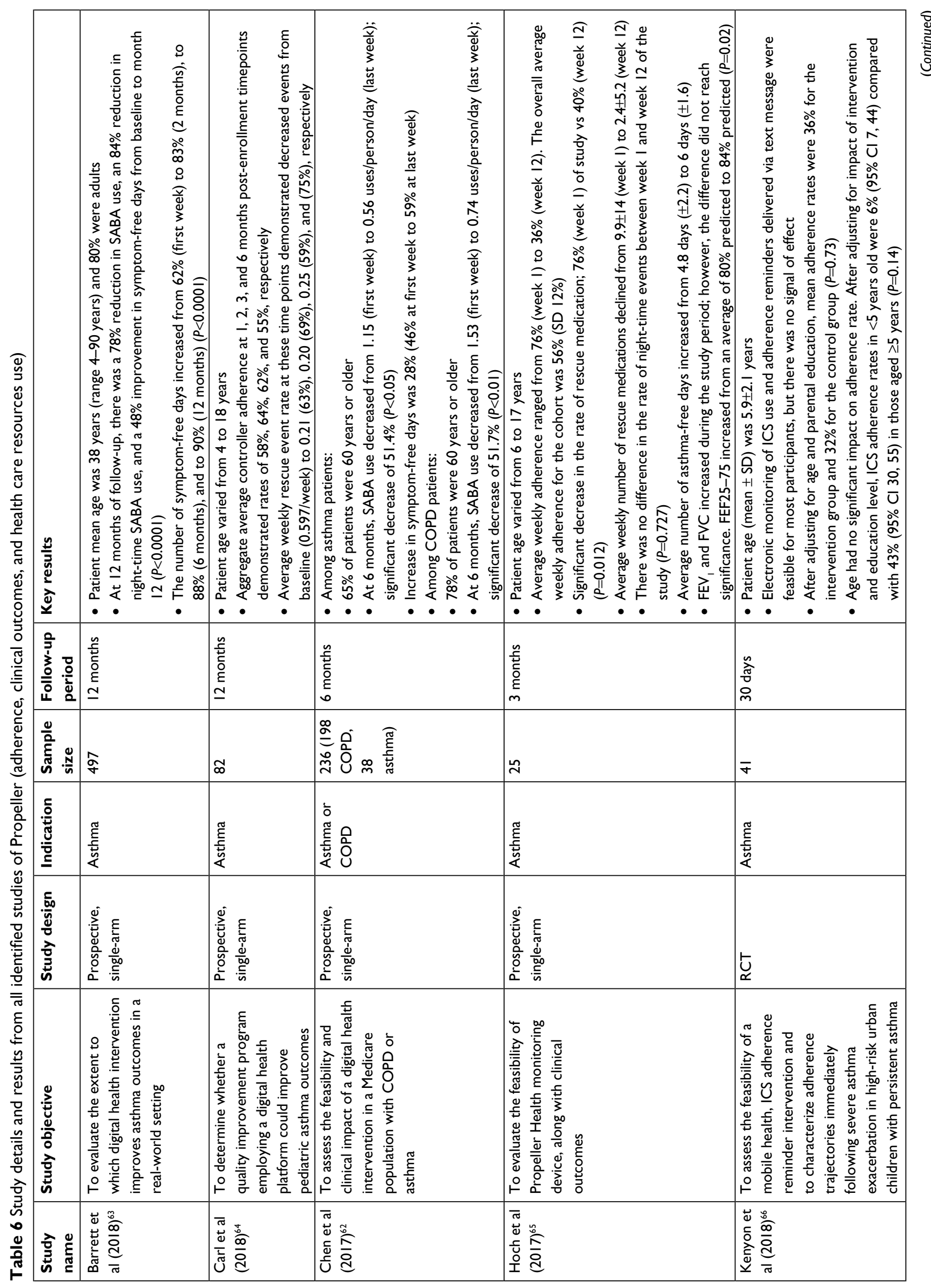




\begin{tabular}{|c|c|c|c|c|c|c|}
\hline 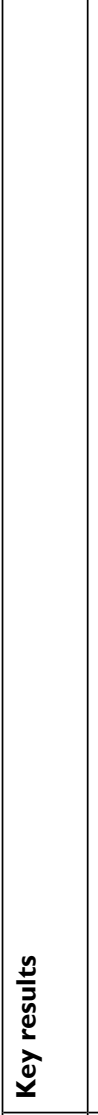 & 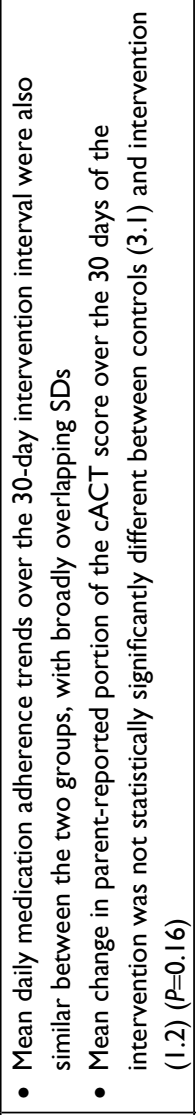 & 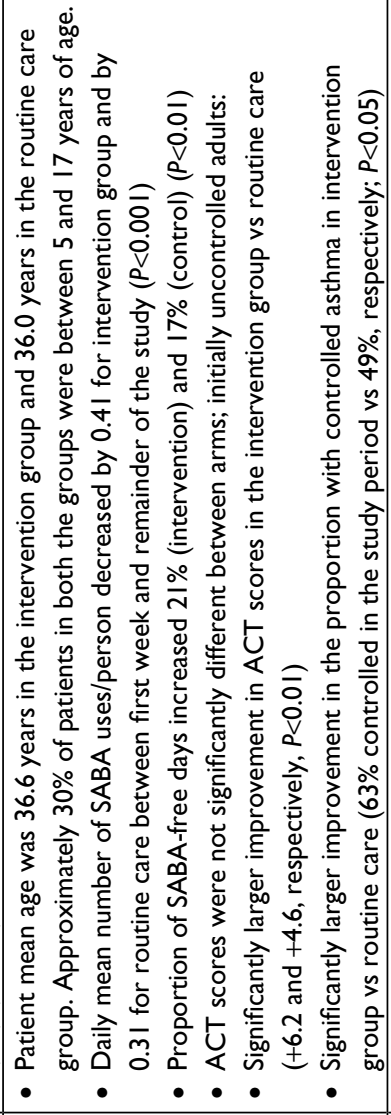 & 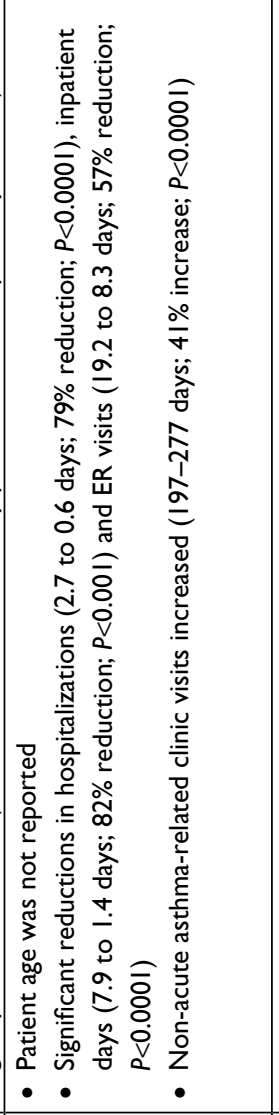 & 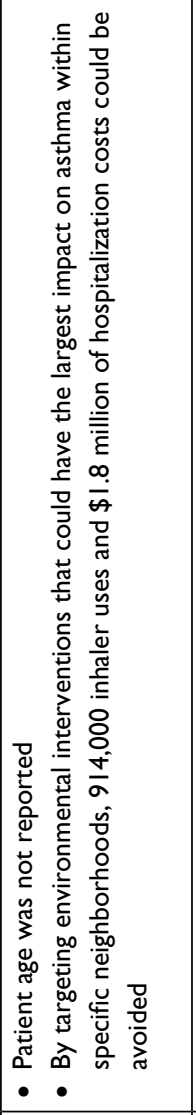 & 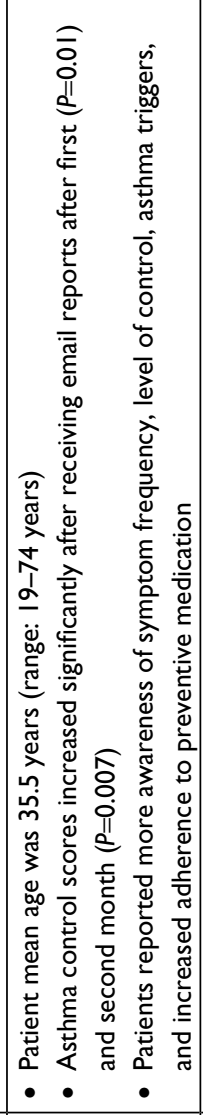 & 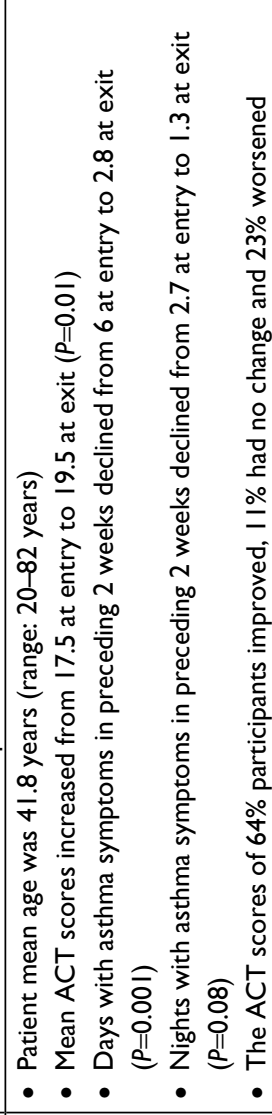 \\
\hline 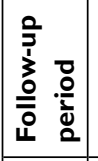 & & 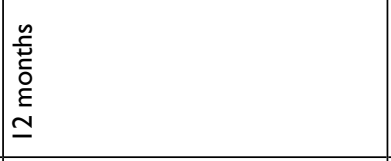 & 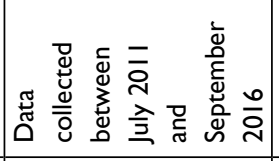 & 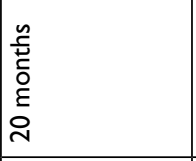 & $\frac{\tilde{c}}{\mathbf{z}}$ & 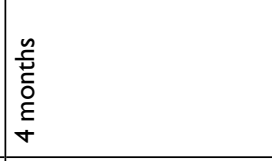 \\
\hline 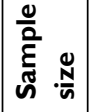 & & 品 & î̀ & of & 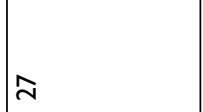 & 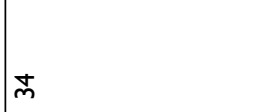 \\
\hline 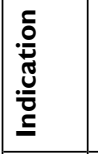 & & 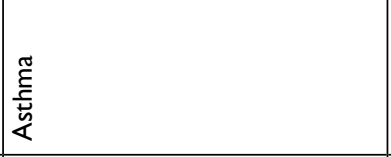 & 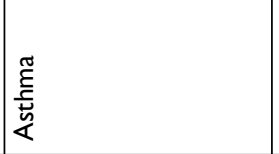 & 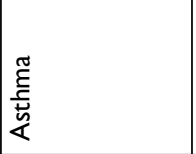 & 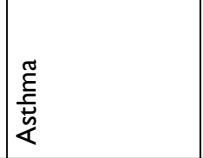 & $\begin{array}{l}\text { 胥 } \\
\text { 妾 }\end{array}$ \\
\hline 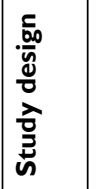 & & & 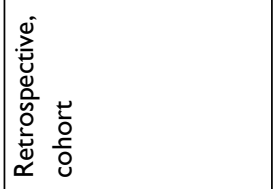 & 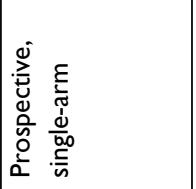 & 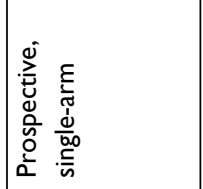 & 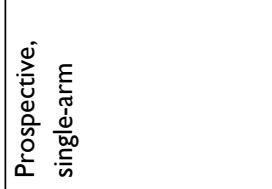 \\
\hline 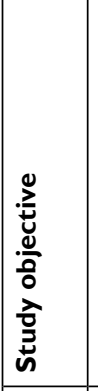 & & 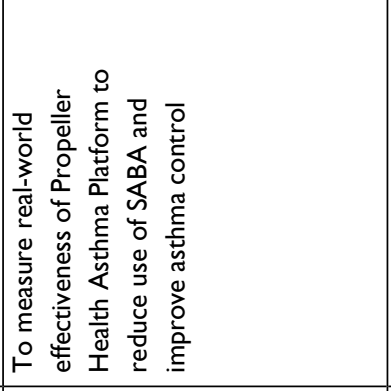 & 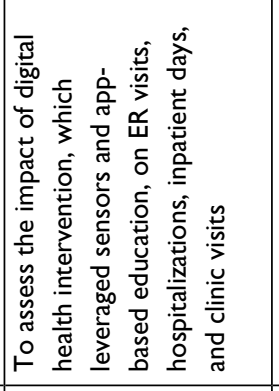 & 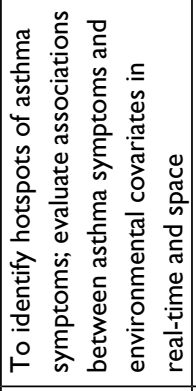 & 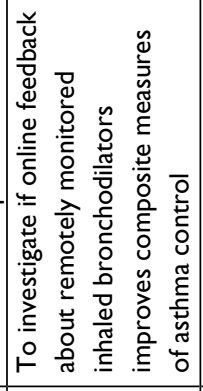 & 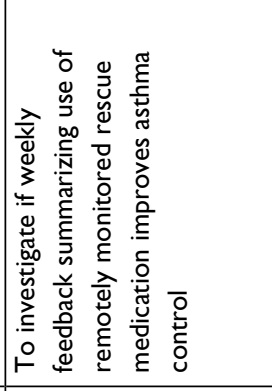 \\
\hline 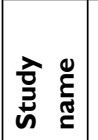 & & 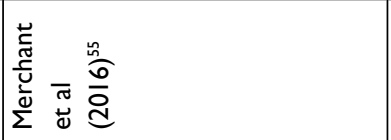 & 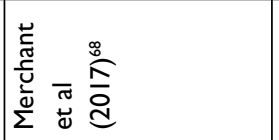 & 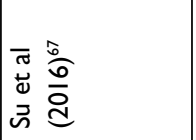 & 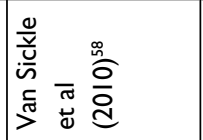 & 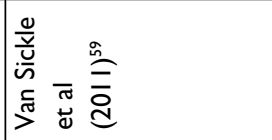 \\
\hline
\end{tabular}




\begin{tabular}{|c|c|c|c|}
\hline 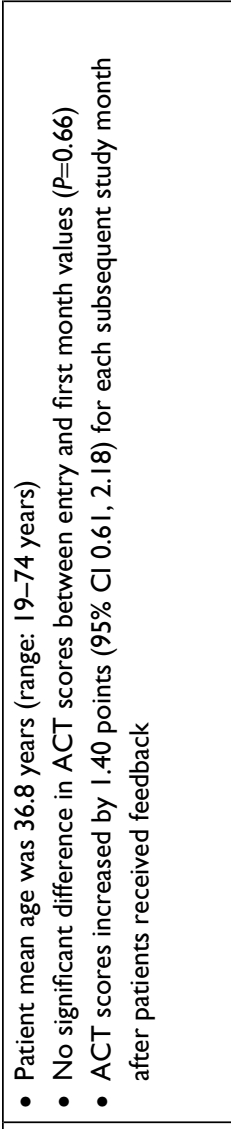 & 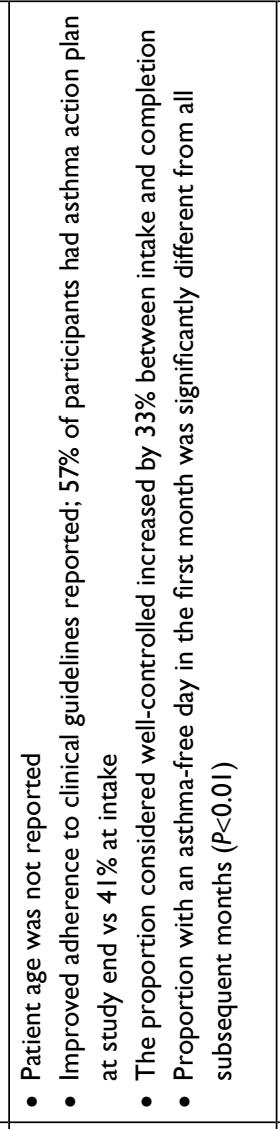 & 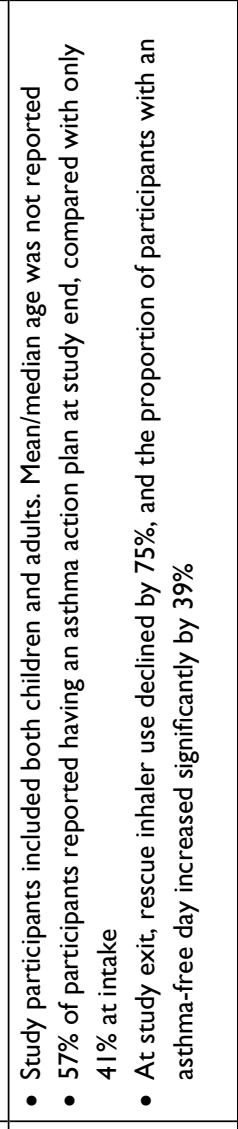 & 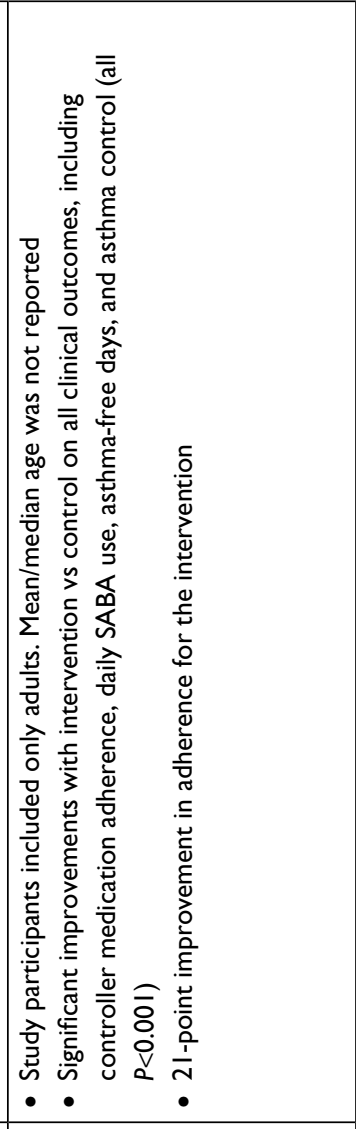 \\
\hline & 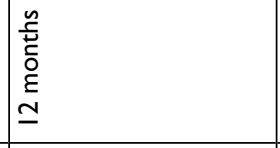 & 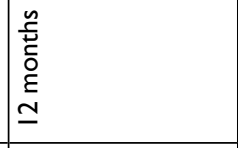 & 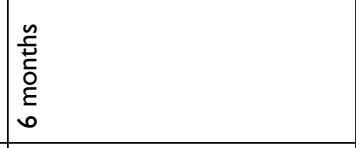 \\
\hline ஓ & 兄 & $\stackrel{\alpha}{\text { ( }}$ & $\stackrel{\sim}{\cong}$ \\
\hline & 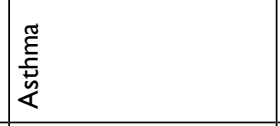 & 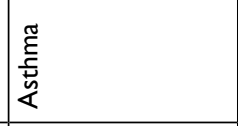 & 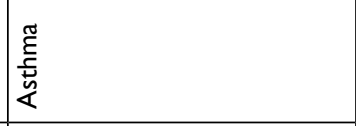 \\
\hline 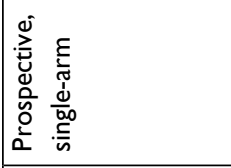 & 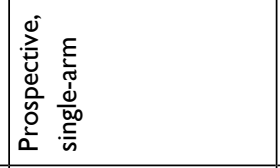 & 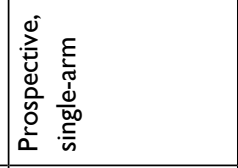 & $\mid \begin{array}{c}\mathfrak{y} \\
\propto\end{array}$ \\
\hline 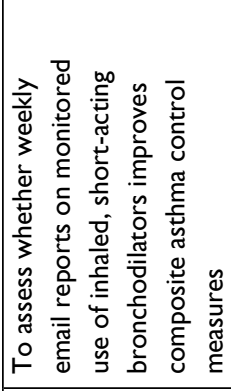 & 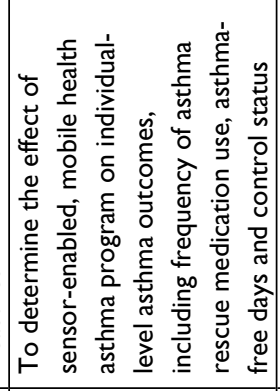 & 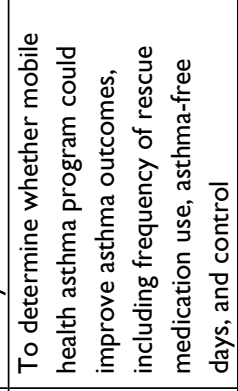 & 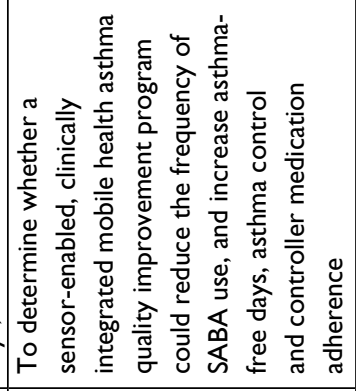 \\
\hline 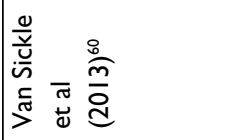 & 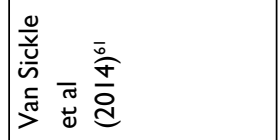 & 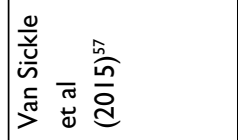 & 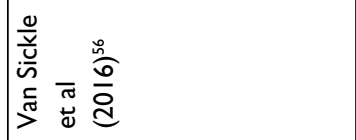 \\
\hline
\end{tabular}


improvement in adherence in the intervention group, significant improvements in controller medication adherence, daily SABA use, asthma-free days, and asthma control were reported.

In 2015, Van Sickle et $\mathrm{al}^{57}$ published the results from a study in 299 asthma patients with a SABA prescription. The initial control period was 30 days and the subsequent period during which patients received the smartphone and webbased self-management tool was 12 months. At follow-up, rescue inhaler use declined by $75 \%$, and the proportion of participants with an asthma-free day increased by $39 \%$. The proportion with asthma-free days during the initial control period was significantly lower than all subsequent months, and the proportion considered well-controlled increased by $33 \%$ between intake and exit. In addition, while only $41 \%$ of patients were reported to have an asthma action plan at study entry, $57 \%$ had one at the end of the trial. Similar findings were reported in a number of other non-randomized trials. ${ }^{58-65}$

Suboptimal adherence trajectories following severe exacerbations independent of the use of daily text message reminders by means of the Propeller system were reported by Kenyon et al. ${ }^{66}$ In their study, children aged $2-13$ years with persistent asthma were randomized to an intervention group (receiving daily text message reminders, including tips about the value of regular controller use) or control group (receiving only two reminders to sync their sensors). The impact of patient age on adherence to study treatments was assessed. After adjusting for age and parental education, mean adherence rates were $36 \%$ and $32 \%$ for the intervention and control groups, respectively. Mean daily medication adherence trends over the 30-day intervention were also similar between the two groups, with broadly overlapping standard deviations. In addition, mean change in the parent-reported portion of the childhood asthma control test (cACT) score over the 30 days was not statistically significantly different between controls (3.1) and intervention (1.2). While the study was not powered to analyze adherence, there was no signal of impact due to the text message intervention.

In a model of the impact of municipal intervention scenarios based on data from 140 asthma patients recording inhaler use with a wireless sensor that passively collected date, time, and location of inhaler use in Louisville between June 2012 and February 2014, it was estimated that \$1.8 million in hospitalization costs could be avoided through targeted use of interventions such as the Propeller device. ${ }^{67}$

A retrospective study of electronic medical records compared asthma-related and non-asthma-related utilization event rates among 507 asthma patients during the intervention period (use of Propeller Sensor) to those during their preintervention baseline. ${ }^{68}$ All acute asthma-related utilization rates demonstrated significant reductions, including hospitalizations (2.7 to 0.6 days), inpatient days (7.9 to 1.4 days), and emergency department visits (19.2 to 8.3 days), while nonacute asthma-related clinic visits increased (197 to 277 days). Moreover, there was a non-statistically significant decrease in all non-asthma utilization events, including hospitalizations, emergency department visits, and clinic visits. The authors suggested that the increase in clinic visits may be related to providers making an attempt to address patient worsening in a non-acute setting before an acute exacerbation occurred.

\section{Discussion and conclusion}

From the five preselected connected drug delivery devices, the two that were developed by the manufacturer of combined interferons (RebiSmart ${ }^{\circledR}$ and BETACONNECT ${ }^{\mathrm{TM}}$ ) showed high adherence rates of $>80 \%$ to $90 \%$ overall. In addition, as assessed with the RebiSmart ${ }^{\circledR}$ device, there was a correlation between higher adherence and a number of efficacy outcomes. Nevertheless, it cannot be concluded that the observed compliance with the dosing regimen was a result of the application of connected features, as the relevant trials did not include a control arm.

A different database is available for devices that were developed by specialized biotech companies aiming to apply their technologies to molecules and devices developed by potential pharma partners (Proteus Discover, SmartInhaler ${ }^{\mathrm{TM}}$, Propeller). As part of the overall value proposition, studies have been conducted comparing adherence to treatment and related outcomes with and without connected device features. Collectively, clinical studies demonstrate improved adherence to treatment with the connected device vs standard of care, with a number of trials revealing a correlation between adherence and efficacy outcomes. In addition, there is initial evidence that the use of connected devices could result in lower health care costs due to reductions in outpatient and inpatient services, patient monitoring, disease management, and medication costs.

Therefore, considering together the data available for the different connected devices, there is initial evidence that such tools could be a cost-effective modality to improve adherence to treatment and ultimately outcomes outside of a controlled stetting. Thus, digital homecare is expected to decrease uncertainty around patient adherence, while maintaining patient-centric disease management.

Through real-time collection of patient health and disease state information, connected devices can promote the 
early tracking of potential adverse events or complications, allowing physicians to differentiate between pharmacological resistance and improper medication use. This may prevent severe treatment-related events or treatment failure that would otherwise consume costs and resources (including hospitalization) and enable real-time decision-making concerning continuation of treatment (including whether to maintain or alter the dose) or treatment discontinuation.

Connected drug delivery devices may also play a role in complementing value-based reimbursement models. Longterm reimbursement decisions for the "companion drug" might be supported with adherence or PRO data derived from these technologies. Such data could be used to support performance and value-based payment solutions by tracking the ongoing performance post-approval to confirm the outcomes of RCTs in the real-world setting.

To ensure broad acceptance of connected devices, however, a number of barriers still need to be overcome (Figure 1). Despite initial enthusiasm, patients may lose motivation over time, which is difficult to show in a clinical trial setting. Not all patients will want to share their data with HCPs or payers, and depending on the area where people live, connectivity issues may prevent continuous application of the electronic device. In addition, as reasons for nonadherence depend on the patient and patient population, customized connected tools tailored to individual patients, patient populations, and indications need to be made available. From an HCP perspective, there will likely be concerns about lack of remuneration for patient training, data capture, and assessment. Also, aspects of reliability, completeness, and security of the data, as well as the perceived lack of control and direct patient contact while still being liable for the treatment, need to be further addressed. To unfold the full potential of connected devices from an HCP and payer perspective, more data on the health economic benefit need to become available on an individual drug and/or indication basis. The increasingly stringent laws around data privacy and patient security also have to be taken into consideration in this context. For example, the new European regulations on personal data protection that came into effect in May 2018 across its Member States ${ }^{69,70}$ will impact the European setting for connected devices and health apps. The full set of its implications on the environment for connected devices and related health apps will not be fully understood and visible for a few years.

It is expected that future connected device features enabling drug delivery in the home setting may be further improved technically by considering aspects such as patient age, general customization to individual patient needs, as well as a combination of different adherence tools. Studies on the impact of patient age on the successful use of connected

Payer

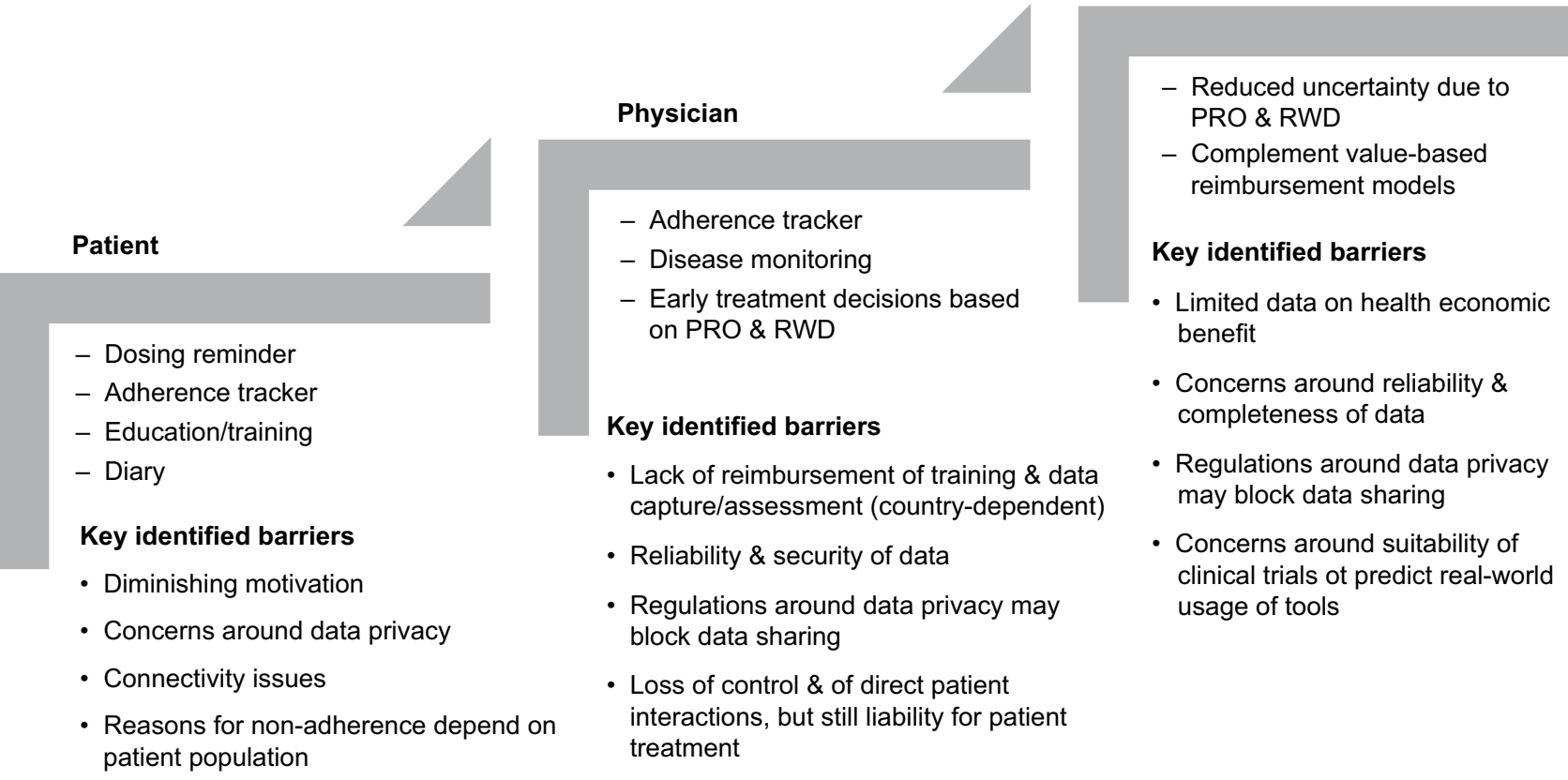

Figure I Expected value of connected devices for stakeholders and potential barriers to adoption.

Abbreviations: PRO, patient-reported outcome; RWD, real-world data. 
devices are still limited. More work in this area is mandated, as one potential challenge with the widespread use of connected devices is the requirement to develop a certain level of computer skills in computer-naive patients. Interestingly, however, in a study with the RebiSmart, older age was associated with a higher objective adherence. ${ }^{25}$ In contrast, Barone et $\mathrm{al}^{71}$ reported a greater preference for BETACONNECT ${ }^{\mathrm{TM}}$ among younger patients (100\% in patients aged $18-40$ years) compared with older patients $(75 \%$ in patients aged $51-70$ years). Furthermore, older patients were less likely to switch away from standard injection.

In this context it becomes evident that a customization of connected device features should not only relate to a patient's age but also to other individual needs that are specific to the person, medication, and timing of drug intake. As already seen in the field of asthma and chronic obstructive diseases, depending on individual patient needs, electronic devices are complemented with text messaging and self-managing tools (ie, web-based and mobile apps to record symptoms and monitor the disease). ${ }^{72}$ To permit a user-centered design in engaging individuals in behavior change, patients should even be involved in designing the most appropriate adherence tool. ${ }^{73}$

To further improve compliance with the treatment regimen outside the setting of a controlled hospital or physician's office, a combination of different adherence tools has already been proposed with the aim of tracking and overcoming a number of factors leading to poor adherence. Kalantarian et $\mathrm{al}^{74}$ described a two-step system for detecting when a pill bottle is opened using commercial smart-bottle technologies, and when a pill is consumed using a custom-designed smart necklace equipped with a piezoelectric sensor. The authors suggested that combining these two mechanisms coupled with a mobile app could passively monitor adherence and inform caregivers of patient status.

The field of connected drug delivery devices is evolving rapidly. In particular, with the first FDA-approved smart pen for insulin launched in $2017^{75}$ and a number of similar devices in late-stage development, the clinical database on the usefulness of electronic adherence tools linked to drug delivery devices is expected to increase significantly in the near future.

In summary, connected drug delivery devices offer the potential to ensure a high quality of care while supporting drug administration in a decentralized setting. There is already a comparatively large database on the impact of connected features on adherence to treatment and efficacy outcomes. To further apply data generated by connected devices for enabling early treatment decisions and to even complement value-based reimbursement models, aspects such as HCP reimbursement, data reliability, as well as data privacy need to be assessed in greater detail.

\section{Acknowledgments}

The authors acknowledge Magdalena Wanner for support in literature search and documentation. The authors would also like to thank Rachel Danks for assistance with the preparation of this manuscript. The literature review and editorial assistance for the manuscript was funded by F. Hoffmann-La Roche.

\section{Disclosure}

BB, CSC, and JS are employed by F. Hoffman-La Roche Ltd. The authors report no other conflicts of interest in this work.

\section{References}

1. Chee TT, Ryan AM, Wasfy JH, Borden WB. Current state of value-based purchasing programs. Circulation. 2016;133(22):2197-2205.

2. Le Masson G, Solé G, Desnuelle C, et al. Home versus hospital immunoglobulin treatment for autoimmune neuropathies: a cost minimization analysis. Brain Behav. 2018;8(2):e00923.

3. Bittner B, Richter W, Schmidt J. Subcutaneous administration of biotherapeutics: an overview of current challenges and opportunities. BioDrugs. 2018;32(5):425-440.

4. Allan S. Advanced Delivery Devices - How data hubs \& smart devices are enabling the rise of therapeutic ecosystems. Drug Development \& Delivery. January/February 2016. Available from: https://drug-dev.com/ advanced-delivery-devices-how-data-hubs-smart-devices-are-enablingthe-rise-of-therapeutic-ecosystems/. Accessed November 2, 2018.

5. Adherium. Adherium Launches the Hailie ${ }^{\mathrm{TM}}$ Global Brand to Connect People with Asthma and COPD to Better Care [press release]. Available from: https://www.adherium.com/news/adherium-launches-the-hailieglobal-brand-to-connect-people-with-asthma-and-copd-to-better-care/. Accessed November 2018.

6. United States Food and Drug Administration. Medical Device Overview. September 9, 2018. Available from: https://www.fda.gov/forindustry/ importprogram/importbasics/regulatedproducts/ucm510630.htm. Accessed November 2018.

7. European Union. Regulation EU 2017/745 of the European Parliament and of the Council of 5 April 2017 on medical devices, amending Directive 2001/83/EC, Regulation EC No 178/2002 and Regulation EC No 1223/2009 and repealing Council Directives 90/385/EEC and 93/42/EEC. April 5, 2017. Available from: https://eur-lex.europa.eu/ legal-content/EN/TXT/PDF/?uri=CELEX:32017R0745. Accessed November 3, 2018.

8. United States Food and Drug Administration. 510(k) Premarket Notification. September 9, 2018. Available from: https://www.accessdata. fda.gov/scripts/cdrh/cfdocs/cfpmn/pmn.cfm. Accessed November 2018.

9. United States Food and Drink Administration. Betaconnect - supplemental BLA letters. September 25, 2015. Available from: https://www. accessdata.fda.gov/drugsatfda_docs/appletter/2015/103471Orig1s518 6ltr.pdf. Accessed November 4, 2018.

10. United States Food and Drink Administration. Drug Approval Package: Abilify MyCite (aripiprazole). September 13, 2017. Available from: https://www.accessdata.fda.gov/drugsatfda_docs/ nda/2017/207202Orig1s000TOC.cfm. Accessed November 4, 2018. 
11. Proteus Digital Health. August 13, 2010. Available from: www.proteus. com/press-releases/proteus-biomedical-announces-european-ce-markapproval-of-ingestible-sensor-and-monitor-system/. Accessed November 4, 2018.

12. Excell S, Thristan M, Dangond F, Marhardt K, St Charles-Krohe M, Turner-Bowker DM. A novel electronic application of patient-reported outcomes in multiple sclerosis - Meeting the necessary challenge of assessing quality of life and outcomes in daily clinical practice. Eur Neurolog Rev. 2014;9(1):49-55.

13. National Institute for Health and Care Excellence. Smartinhaler for asthma. January 11, 2017. Available from: https:/www.nice.org.uk/guidance/mib90/resources/smartinhaler-for-asthma-pdf-63499461673669. Accessed November 4, 2018.

14. Propeller. Propeller Health receives FDA clearance for the Propeller platform in association with GSK's Elipta ${ }^{\circledR}$ inhaler. July 11, 2016. Available from: https:/www.propellerhealth.com/2016/11/07/ propeller-health-receives-fda-clearance-for-the-propeller-platform-inassociation-with-gsks-ellipta-inhaler/. Accessed November 4, 2018.

15. European Medicines Agency. Qualification opinion on ingestible sensor system for medication adherence as biomarker for measuring patient adherence to medication in clinical trials. February 15, 2016. Available from: https://www.ema.europa.eu/documents/regulatory-proceduralguideline/qualification-opinion-ingestible-sensor-system-medicationadherence-biomarker-measuring-patient_en.pdf. Accessed November 4, 2018.

16. Lugaresi A. RebiSmart ${ }^{\mathrm{TM}}$ (version 1.5) device for multiple sclerosis treatment delivery and adherence. Expert Opin Drug Deliv. 2013;10(2): 273-283.

17. Bayas A. Improving adherence to injectable disease-modifying drugs in multiple sclerosis. Expert Opin Drug Deliv. 2013;10(3): 285-287.

18. Bayas A, Ouallet JC, Kallmann B, et al. Adherence to, and effectiveness of, subcutaneous interferon $\beta$-1a administered by RebiSmart $\AA$ in patients with relapsing multiple sclerosis: results of the 1-year, observational smart study. Expert Opin Drug Deliv. 2015;12(8): 1239-1250.

19. Fernández O, Arroyo R, Martínez-Yélamos S, et al. Long-term adherence to IFN beta-1a treatment when using RebiSmart ${ }^{\circledR}$ device in patients with relapsing-remitting multiple sclerosis. PLoS One. 2016;11(8):e0160313.

20. Paolicelli D, Cocco E, Di Lecce V, et al. Exploratory analysis of predictors of patient adherence to subcutaneous interferon beta-1a in multiple sclerosis: tracer study. Expert Opin Drug Deliv. 2016;13(6):1-7.

21. Devonshire VA, Feinstein A, Moriarty P. Adherence to interferon $\beta$ - $1 \mathrm{a}$ therapy using an electronic self-injector in multiple sclerosis: a multicentre, single-arm, observational, phase IV study. BMC Res Notes. 2016;9:148.

22. Moccia M, Palladino R, Russo C, et al. How many injections did you miss last month? A simple question to predict interferon beta-1a adherence in multiple sclerosis. Expert Opin Drug Deliv. 2015;12(12): 1829-1835.

23. Solsona MDE, Boquet EM, Estruch BC, et al. Impact of adherence on subcutaneous interferon beta-1a effectiveness administered by Rebismart ${ }^{\circledR}$ in patients with multiple sclerosis. Patient Prefer Adherence. 2017:11:415-421.

24. Willis H, Webster J, Larkin AM, Parkes L. An observational, retrospective, UK and Ireland audit of patient adherence to subcutaneous interferon beta-1a injections using the RebiSmart(®) injection device. Patient Prefer Adherence. 2014;8:843-851.

25. Zecca C, Disanto G, Mühl S, Gobbi C. Subjective patient-reported versus objective adherence to subcutaneous interferon $\beta$-1a in multiple sclerosis using RebiSmart ${ }^{\circledR}$ : the CORE study. BMC Neurol. 2017;17(1):171.

26. Pedersen ED, Stenager E, Vadgaard JL, et al. Adherence to subcutaneous interferon beta-1a treatment using an electronic injection device: a prospective open-label Scandinavian noninterventional study (the ScanSmart study). Patient Prefer Adherence. 2018;12:569-575.
27. Rau D, Roßnagel F, Gössling J, et al. Adherence, cognition and behavioral performance in relapsing-remitting MS RRMS patients using the electronic autoinjector RebiSmart: 1 and 2-year follow-up from the German multicenter RebiSmart study. Mult Scler J. 2017;23(3 Suppl):889-890.

28. Lugaresi A, Florio C, Brescia-Morra V, et al. Patient adherence to and tolerability of self-administered interferon $\beta$-1a using an electronic autoinjection device: a multicentre, open-label, phase IV study. $B M C$ Neurol. 2012;12:7.

29. Lugaresi A, De Robertis F, Clerico M, et al. Long-term adherence of patients with relapsing-remitting multiple sclerosis to subcutaneous self-injections of interferon $\beta$-1a using an electronic device: the RIVER study. Expert Opin Drug Deliv. 2016;13(7):931-935.

30. Ghezzi A, Bianchi A, Baroncini D, et al. A multicenter, observational, prospective study of self- and parent-reported quality of life in adolescent multiple sclerosis patients self-administering interferon- $\beta 1 \mathrm{a}$ using RebiSmart ${ }^{\text {TM}}$-the FUTURE study. Neurol Sci. 2017;38(11):1999-2005.

31. Ziemssen T, Sylvester L, Rametta M, Ross AP. Patient satisfaction with the new interferon beta-1b autoinjector (BETACONNECT ${ }^{\mathrm{TM}}$ ). Neurol Ther. 2015;4(2):125-136.

32. Kleiter I, Lang M, Jeske J. Adherence, satisfaction and functional health status among patients with multiple sclerosis using the BETACONNECT $^{\mathrm{TM}}$ autoinjector: a prospective observational cohort study. BMC Neurol. 2017;17(1):174.

33. Patti F, Martínez Ginés ML, Norenberg C, Duarte Caron F. BetaEval Global: Prospective, non-interventional, multinational, observational cohort study of patients using BETACONNECT. Mult Scler J. 2017;23(3 Suppl):954.

34. Rametta M, Germino R, Mcleod K, et al. Impact of Betaconnect autoinjector on patient adherence of betaseron therapy. Annual meeting of the Consortium of Multiple Sclerosis Centers. 2017:May 24-27, New Orleans, LA, USA.

35. Belknap R, Weis S, Brookens A, et al. Feasibility of an ingestible sensorbased system for monitoring adherence to tuberculosis therapy. PLoS One. 2013;8(1):e53373.

36. Frias J, Virdi N, Raja P, Kim Y, Savage G, Osterberg L. Effectiveness of digital medicines to improve clinical outcomes in patients with uncontrolled hypertension and type 2 diabetes: prospective, openlabel, cluster-randomized pilot clinical trial. J Med Internet Res. 2017;19(7):e246.

37. Moorhead P, Zavala A, Kim Y, Virdi NS. Efficacy and safety of a medication dose reminder feature in a digital health offering with the use of sensor-enabled medicines. J Am Pharm Assoc. 2017;57(2):155-161.

38. Dicarlo L, Kim YA, Young J, Bezhadi Y. Real-time assessment of medication taking and activities of daily living in patients with uncontrolled hypertension. Value Health. 2014;17(7):A475.

39. Godbehere P, Wareing P. Hypertension assessment and management: role for digital medicine. J Clin Hypertens. 2014;16(3):235.

40. Naik R, Macey N, West RJ, et al. First use of an ingestible sensor to manage uncontrolled blood pressure in primary practice: the UK hypertension registry. J Community Med Health Educ. 2017;7(1):1-5.

41. Bonacini M, Ya K, Pitney C, et al. A novel digital medicine offering to assess and optimize adherence for oral hepatitis $\mathrm{C}$ treatment. Hepatol. 2017;66(Suppl 1):394A.

42. Sullivan S, Cutright L, McConnell L, et al. Use of digitized medications to enhance adherence and transplant outcomes. Pediatr Transplant. 2017;21(Supplement 1):33.

43. Au-Yeung KY, DiCarlo L. Cost comparison of wirelessly vs directly observed therapy for adherence confirmation in anti-tuberculosis treatment. Int J Tuberc Lung Dis. 2012;16(11):1498-1504.

44. Kim YA, Virdi N, Raja P, Dicarlo L. Modeling the impact of a digital health feedback system in uncontrolled hypertensive patients. Value Health. 2014;17(7):A479.

45. Kim YA, Raja P, Dicarlo L, Virdi N, Park H. An economic model of the impact of digital medicines with a mobile application in patients with comorbid hypertension, diabetes, and hypercholesterolemia. Value Health. 2015;18(3):A40. 
46. Chen AH, Harrison J, Black PN, Mitchell EA, Foster JM. Using electronic monitoring devices to measure inhaler adherence: a practical guide for clinicians. JAllergy Clin Immunol Pract. 2015;3(3):335-349.

47. Morton RW, Elphick HE, Rigby AS, et al. STAAR: A randomised controlled trial of electronic adherence monitoring with reminder alarms and feedback to improve clinical outcomes for children with asthma. Thorax. 2017;72(4):347-354.

48. Chan AHY, Stewart AW, Harrison J, Camargo CA, Black PN, Mitchell EA. The effect of an electronic monitoring device with audiovisual reminder function on adherence to inhaled corticosteroids and school attendance in children with asthma: a randomised controlled trial. Lancet Respir Med. 2015;3(3):210-219.

49. Burgess SW, Sly PD, Devadason SG. Providing feedback on adherence increases use of preventive medication by asthmatic children. JAsthma. 2010;47(2):198-201.

50. Charles T, Quinn D, Weatherall M, Aldington S, Beasley R, Holt S. An audiovisual reminder function improves adherence with inhaled corticosteroid therapy in asthma. J Allergy Clin Immunol. 2007;119(4):811-816.

51. Foster JM, Usherwood T, Smith L, et al. Inhaler reminders improve adherence with controller treatment in primary care patients with asthma. J Allergy Clin Immunol. 2014;134(6):1260-1268.

52. Britto MT, Rohan JM, Dodds CM, Byczkowski TL. A randomized trial of user-controlled text messaging to improve asthma outcomes: a pilot study. Clin Pediatr. 2017;56(14):1336-1344.

53. Kenyon CC, Chang J, Wynter SA, Fowler JC, Long J, Bryant-Stephens TC. Electronic adherence monitoring in a high-utilizing pediatric asthma cohort: a feasibility study. JMIR Res Protoc. 2016;5(2):e132.

54. Merchant R, Inamdar R, Henderson K, et al. Digital health intervention for asthma: patient-reported value and usability. JMIR Mhealth Uhealth . 2018;6(6):e133.

55. Merchant RK, Inamdar R, Quade RC. Effectiveness of population health management using the propeller health asthma platform: a randomized clinical trial. J Allergy Clin Immunol Pract. 2016;4(3):455-463.

56. Van Sickle D, Barrett M, Humblet O, et al. Randomized, controlled study of the impact of a mobile health tool on asthma SABA use, control and adherence. Eur Respir J. 2016;48:PA1018.

57. Van Sickle D, Su J, Barrett M, et al. Impact of a mobile health pilot study on asthma rescue inhaler use, control and self-management. Eur Respir J. 2015;46:PA2528.

58. Van Sickle D, Magzamen S, Truelove S. Online feedback about remotely monitored inhaled bronchodilators improves composite measures of asthma control. Am J Respir Crit Care Med. 2010;181:A3127.

59. Van Sickle D, Morrison TA. Weekly feedback summarizing use of remotely monitored rescue medication improves asthma control. Am J Respir Crit Care Med. 2011;183:A4755.

60. Van Sickle D, Magzamen S, Truelove S, et al. Remote monitoring of inhaled bronchodilator use and weekly feedback about asthma management: an open-group, short-term pilot study of the impact on asthma control. PLoS One. 2013;82:e55335.

61. Van Sickle D, Barrett M, Marcus J, Humblet O. Smith T. Impact of a technology-driven asthma program on symptoms, control and selfmanagement: the clinical perspective. $142^{\text {nd }}$ APHA Annual Meeting \& Exposition 2014 Annual Meeting \& Exposition: New Orleans, LA, USA; 2014:303269.

62. Chen JS, Jones-Ford GS, Tuffli M, Barrett M, van Sickle D. Feasibility and clinical impact of deploying a digital health intervention in a Medicare population with COPD. Am J Respir Crit Care Med. 2017;195:A1722.
63. Barrett M, Combs V, Su JG, et al. AIR Louisville: Addressing asthma with technology, crowdsourcing, cross-sector collaboration, and policy. Health Aff. 2018;37(4):525-534.

64. Carl JC, Isakov D, Winners $\mathrm{S}$, et al. Use of remote electronic monitoring improves asthma outcomes through improved adherence. Am J Resp Crit Care Med. 2018;197:A1164.

65. Hoch H, Meier MR, Brinton JT, Szefler SJ. A feasibility study of daily monitoring of controller and rescue medication use in a pediatric patient population at high risk of an asthma exacerbation. Am J Resp Crit Care Med. 2017;195:A198.

66. Kenyon CC, Gruschow SM, Quarshie WO, et al. Controller adherence following hospital discharge in high risk children: a pilot randomized trial of text message reminders. J Asthma. 2018;13:1-9.

67. Su J, Barrett M, Henderson K, et al. Application of wireless inhaler sensors to enhance asthma surveillance and inform municipal interventions. APHA 2016 Annual Meeting \& Exposition: Denver, CO, USA. 2016;4382.

68. Merchant R, Tuffli M, Barrett M, et al. Impact of a digital health intervention on asthma healthcare utilization. Eur Respir J. 2017;50: PA4692.

69. European Commission. What does the general data protection regulation (GDPR) govern? 2018. Available from. Available from: https:// ec.europa.eu/info/law/law-topic/data-protection/reform/what-doesgeneral-data-protection-regulation-gdpr-govern_en. Accessed November 2018.

70. European Union. Regulation (EU) 2016/679 of the European Parliament and of the council of 27 April 2016 on the protection of natural persons with regard to the processing of personal data and on the free movement of such data, and repealing Directive 95/46/EC (General Data Protection Regulation). April 27, 2016. Available from https:// eur-lex.europa.eu/legal-content/EN/TXT/PDF/?uri=CELEX:32016R 0679\&from=EN. Accessed November 2018.

71. Barone DA, Singer BA, Merkov L, Rametta M, Suarez G. Survey of US patients with multiple sclerosis: comparison of the new electronic interferon beta- $1 \mathrm{~b}$ autoinjector (BETACONNECT ${ }^{\mathrm{TM}}$ ) with mechanical autoinjectors. Neurol Ther. 2016;5(2):155-167.

72. Blakey JD, Bender BG, Dima AL, et al. Digital technologies and adherence in respiratory diseases: the road ahead. Eur Respir J. 2018;52(5):180114722 112018.

73. Blixen C, Sajatovic M, Moore DJ, et al. Patient participation in the development of a customized $\mathrm{m}$-Health intervention to improve medication adherence in poorly adherent individuals with bipolar disorder (BD) and hypertension (HTN). Int J Healthc. 2018;4(1):25-35.

74. Kalantarian H, Motamed B, Alshurafa N, Sarrafzadeh M. A wearable sensor system for medication adherence prediction. Artif Intell Med. 2016;69:43-52.

75. Klonoff DC, Kerr D. Smart pens will improve insulin therapy. J Diabetes Sci Technol. 2018;12(3):551-553.

76. Järvinen E, Multanen J, Atula S. Subcutaneous interferon $\beta$-1a administration by electronic auto-injector is associated with high adherence in patients with relapsing remitting multiple sclerosis in a real-life study. Neurol Int. 2017;9(1):6957.

77. Virdi NS, Kim Y, Raja P, Savage G, Osterberg L. Optimizing treatment in patients with uncontrolled hypertension and type 2 diabetes by using a digital health offering. J Am Soc Hypertens. 2016;10(4): e72-e73.

78. Jochmann a, Nagakumar P, Hall P, et al. Improvement in asthma control and airway inflammation during a period of electronic monitoring. Eur Respir Soc. 2015;46:OA4775. 


\section{Supplementary materials}

Table SI Predefined research questions

Research questions

- Is there any regulatory/HTA guidance for connected devices in the US and EU, including apps or software in particular?

- What was the approval pathway for any connected devices that have been reviewed by regulatory authorities?

- Which clinical studies or other studies were required by regulatory and HTA bodies in order to grant approval of the selected connected devices?

- What is the impact of selected connected devices on adherence (clinical studies or RWE)?

- What is the impact of selected connected devices on clinical outcomes?

- What is the impact of selected connected devices on health care costs and resources, including doctors' visits (scheduled and unscheduled visits)?

- What are the potential barriers that need to be overcome to unfold the full potential of these tools?

Abbreviations: EU, European Union; HTA, Health technology assessment; RWE, real-world evidence; US, United States.

Table S2 Data sources searched

Data sources searched
PubMed
Google
Google Scholar
Company websites
HTA databases (AETSA; AHRQ; CADTH; CTAF-ICER; HAS; INAHTA; IQWiG; NHS; NICE; PBAC; SMC)
USFDA website
EMA website
Clinicaltrials.gov
International Clinical Trials Registry Platform

Abbreviations: AETSA, Agencia de Evaluación de Tecnologías Sanitarias de Andalucía: AHRQ, The Agency for Health care Research and Quality; CADTH Canadian Agency for Drugs and Technologies in Health; CTAF-ICER, The California Technology Assessment Forum - Institute for Clinical and Economic Review; EMA, European Medicines Agency; HAS, Haute Autorité de Santé; HTA, Health technology assessment; INAHTA, The International Network of Agencies for Health Technology Assessment; IQWiG, The Institute for Quality and Efficiency in Health care; NHS, National Health Service; NICE, National Institute for Health and Clinical Excellence; PBAC, Pharmaceutical Benefits Advisory Committee; SMC, Scottish Medicines Consortium; USFDA, United States Food and Drug Administration.

Table S3 Search terms used

\begin{tabular}{|l|l|}
\hline Device & Synonym/local language translation \\
\hline Proteus Discover & $\begin{array}{l}\text { Proteus pill, Proteus patch, and other translated terms of the device in different languages (eg, Proteus-Pille [German], } \\
\text { Proteus pillola [Italian], pilule Proteus [French], pildora de Proteus [Spanish]) }\end{array}$ \\
\hline RebiSmart ${ }^{\circledR}$ & Msdialog and other translated terms of the device in different languages (same as that of English) \\
\hline BETACONNECT TM & $\begin{array}{l}\text { BETACONNECT }{ }^{\text {M }} \text { system, BETACONNECT TM, and other translated search terms of the device in different languages } \\
\text { (eg, Beta verbinden [German], Beta connettersi [Italian]; while French and Spanish terms remained same as that of English } \\
\text { language) }\end{array}$ \\
\hline SmartInhaler ${ }^{\text {TM }}$ & $\begin{array}{l}\text { Smart inhaler, Smartlnhaler medication sensors, Smartlnhaler sensors, Smartturbo, Smarttouch and other translated terms } \\
\text { of the device in different languages (eg, Intelligenter Inhalator [German], Inalatore intelligente [Italian], Inhalateur intelligent } \\
\text { [French], Inhalador inteligente [Spanish]) }\end{array}$ \\
\hline Propeller & $\begin{array}{l}\text { Propeller Sensor, specific device terms including Ellipta, Respimat, Diskus, MDI, metered-dose inhaler, and other translated } \\
\text { terms of the device in different languages (eg, Elica [Italian], Hélice [French \& Spanish]); while the German term remained } \\
\text { same as that of English language }\end{array}$ \\
\hline
\end{tabular}

Note: General searches were also undertaken to identify guidance documents for connected devices overall.

Abbreviation: MDI, metered-dose inhaler.

Medical Devices: Evidence and Research

\section{Publish your work in this journal}

Medical Devices: Evidence and Research is an international, peerreviewed, open access journal that focuses on the evidence, technology, research, and expert opinion supporting the use and application of medical devices in the diagnosis, monitoring, treatment and management of clinical conditions and physiological processes. The identification of novel
Dovepress

devices and optimal use of existing devices which will lead to improved clinical outcomes and more effective patient management and safety is a key feature. The manuscript management system is completely online and includes a quick and fair peer-review system. Visit http://www. dovepress.com/testimonials.php to read real quotes from authors.

Submit your manuscript here: https://www.dovepress.com/medical-devices-evidence-and-research-journal 